Library and Archives

Canada

Published Heritage

Branch

395 Wellington Street

Ottawa ON K1A ON4

Canada
Bibliothèque et

Archives Canada

Direction du

Patrimoine de l'édition

395 , rue Wellington

Ottawa ON K1A ON4

Canada
Your file Votre référence

ISBN: 978-0-494-93643-6

Our file Notre référence

ISBN: $978-0-494-93643-6$
NOTICE:

The author has granted a nonexclusive license allowing Library and Archives Canada to reproduce, publish, archive, preserve, conserve, communicate to the public by telecommunication or on the Internet, loan, distrbute and sell theses worldwide, for commercial or noncommercial purposes, in microform, paper, electronic and/or any other formats.

The author retains copyright ownership and moral rights in this thesis. Neither the thesis nor substantial extracts from it may be printed or otherwise reproduced without the author's permission.
AVIS:

L'auteur a accordé une licence non exclusive permettant à la Bibliothèque et Archives Canada de reproduire, publier, archiver, sauvegarder, conserver, transmettre au public par télécommunication ou par l'Internet, prêter, distribuer et vendre des thèses partout dans le monde, à des fins commerciales ou autres, sur support microforme, papier, électronique et/ou autres formats.

L'auteur conserve la propriété du droit d'auteur et des droits moraux qui protege cette thèse. $\mathrm{Ni}$ la thèse ni des extraits substantiels de celle-ci ne doivent être imprimés ou autrement reproduits sans son autorisation.
In compliance with the Canadian Privacy Act some supporting forms may have been removed from this thesis.

While these forms may be included in the document page count, their removal does not represent any loss of content from the thesis.
Conformément à la loi canadienne sur la protection de la vie privée, quelques formulaires secondaires ont été enlevés de cette thèse.

Bien que ces formulaires aient inclus dans la pagination, il n'y aura aucun contenu manquant. 


\title{
The Cacophony of Space and the Clink Clunk Clang in Architecture The mall corridor redux.
}

\author{
by \\ Nolan Cipriano
}

A thesis submitted to the Faculty of Graduate and Postdoctoral Affairs in partial fulfillment of the requirements for the degree of

Masters of Archtiecture

Carleton University

Ottawa, Ontario

(C) 2012

Nolan Cipriano 


\section{Abstract}

The element of sound is nearly inescapable. The various ways in which sound is generated, perceived, represented, and hindered resonates not only within the realm of the auditory sense, but as well as the visual and tactile. Through investigating the representation of sound, both in the aural and visual worlds, a deeper understanding of its profound effects can be observed.

In the world of architectural space it is the element of sound that is often forgotten, whereas the sonic nature of a space is not designed. This thesis endeavours to examine how, through a comprehensive understanding of the various facets of sound representations, effects, and history, it can inform specifically designed sonorously beneficial spaces that directly reflect and support their purpose. This notion will be explored through the redesign of the shopping-mall corridor within the heritage structure of the Ogilvy Building in Ottawa, Ontario. Through adaptive architecture, the possibility exists to create a subjective aural space. 
"Tell me, have you noticed walking

about the city, that among the

buildings it is peopled, certain are mute;

others speak; and others,

finally, and they are the most rare-

sing?"

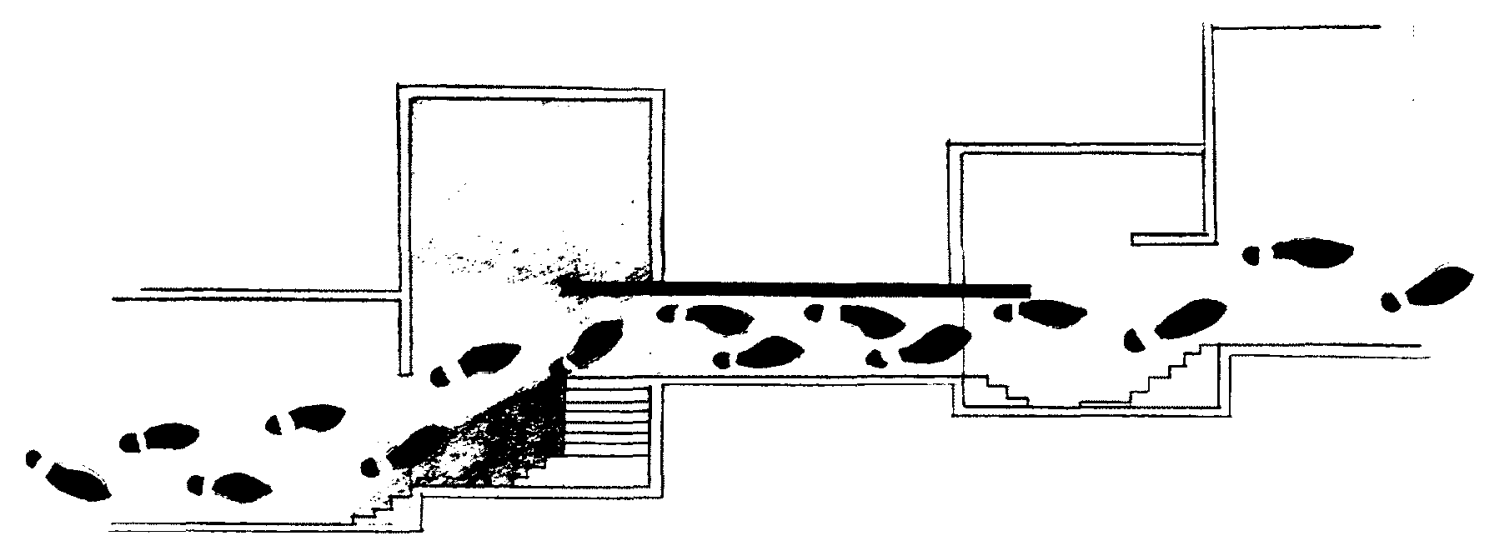




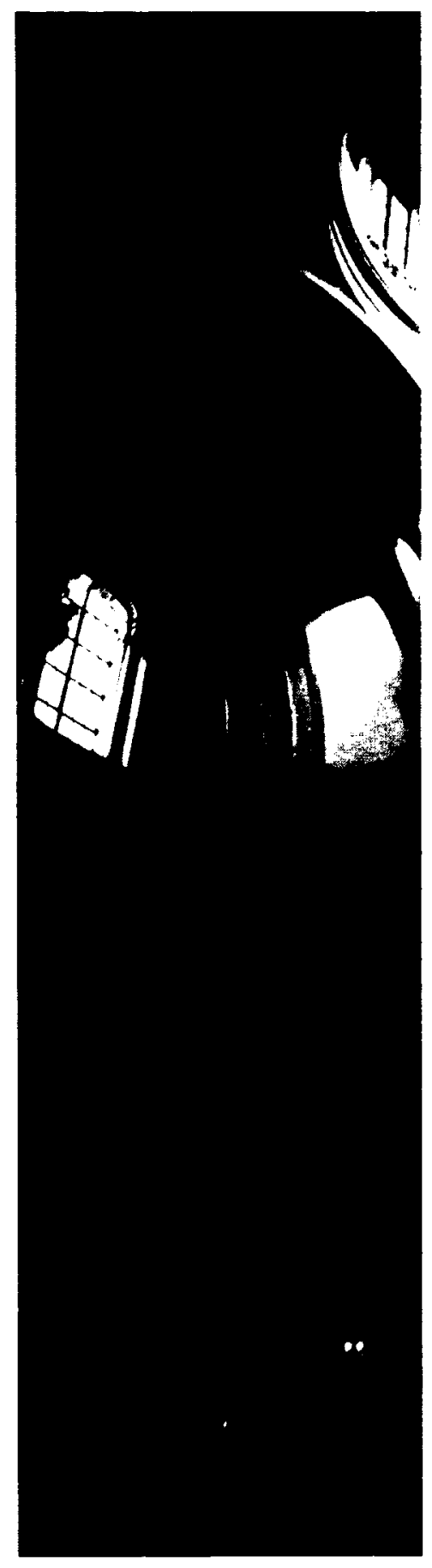

I would like to acknowledge all those who have supported me and helped me achieve this great success.

Special thanks to Federica Goffi for mentoring me over the years

for I could not have done this without her.

And To Claudio Sgarbi, and Dipna Horra for their interest and contributions.

For my Family 


\section{Contents}

List of Illustrations

Glossary of Terms

Introduction.
Page 6

Page 7

Page 10

Part 1: The Sonic Boom and the ever-happening cacophony of noise. The physiological, psychological, and cultural effects of clatter.

Page 15

a preamble to noise

Part 2: The Manifestation of Sound Did you see that? It was so loud! - Sound interpretation from Russolo and the Futurists, to the avant-garde poet, to Nono, Xenakis and Byrne.

Page 19

Part 3: The Project Site - The Ogilvy Building and the Rideau Centre

Page 33

Part 4: Dissecting the mall.

Page 38

Part 5: Reassembling the sonic corridor as a musical composition. The heritage Ogilvy Building in downtown Ottawa

Conclusion

Page 44

List of Figures

Page 55

Bibliography

Page 58

Page 60 


\section{List of Illustrations}

1. Footsteps Drawing

2. Basilica San Luca

3. Luigi Russolo

4. The Ark Sketch

5. The Ark

6. Xenakis: Metastasis Score

7. Xenakis: Musical Score

8. Xenakis: Terretektorh Score

9. Xenakis: Metastasis Glissando

10. Philips Pavilion

11. Philips Pavilion Image

12. Playing the Building

13. Rideau Centre Plan

14. Rideau Centre

15. Site Plan

16. Ogilvy Building North Facade Detail

17. Ogilvy Building North-East Corner

18. Ogilvy Building East Facade Detail

19. Ogilvy Building South Facade Detail

20. West Edmonton Mall

21.Cleveland Arcade

22. Ground Floor Plan

23. Second Floor Plan

24. Third Floor Plan

25. Fourth Floor Plan

26. Fifth Floor Plan

27. Main Atrium Perspective

28. Main Atrium Perspective II

29. Ground Level Entrance Hall

30. Cafe/Performance Area

31. Cafe/Performance Area II

32. North Facade Perspective

33. Building Perspective

34. North-South Section

35. Ground Floor Perspective

36. Second Floor Perspective

37. Speaker Door Detail

38. Ground Level Sound Plan (Open)

39. Ground Level Sound Plan (Closed)

40. Second Floor Sound Plan

41 . North-South Sound Section

42. Sound Section Perspective

43. Ogilvy Building East Facade Detail 


\section{Glossary of Terms}

Acoustics - The science that studies the behavior of sound

Acoustical Memory - Related to Acoustic Ecology; refers to the notion of residual sonorous incidents, and their effect on real-time perception.

Acoustical Archaeologist - An individual who investigates the acoustic and aural conditions of spaces that have since ceased to exist; or have been significantly altered throughout time

Acoustical Footprint - The sound and energy footprint emitted by an individual or an object within space and time.

Acoustic Ecology - The study of sounds and individual entities. Focus on a sounds existence within time; cataloguing endangered or extinct sound (not only organic or biological)

Acousmatic - A sound in which one cannot see its originating source

Abandoned Sound - The forgotten residual imprint left from either an extinct sound, or left within an abandoned space; tied into acoustic $\operatorname{archaeolog} y$

Adaptive Architecture - Architecture that has the ability to change its physical condition and therefore adapt to specific user needs. In changing the physical proportions of a space, other sensory perception also changes (i.e. light and sound conditions)

Stochastic resonance - The tendency of small amounts of noise or other random signals to restore order to an operating system

Infrasound - The sound that is lower in frequency than $20 \mathrm{~Hz}$, cycles per second, the "normal" limit of human hearing 
Sound Vectors - Refers to the directionality of sound. (Important in the study of the echo)

Sonic body - The notion of the body as the source of sound production in varying capacities (internally vs. externally)

Soundscape - The sonic environment. The term may refer to actual environments, or to abstract constructions such as musical composition, particularly when considered as an environment ${ }^{\prime}$

Sound Space - Similar in concept to a soundscape, however, refers primarily to the sonic condition within a given architectural space.

Aural Architecture - The study of architecture with emphasis on ones sonic awareness of space. Far different from acoustics as it takes into account the individual's perceptions with influence from social, cultural, and political factors.

Acoustic horizon - The maximum distance between a listener and source of sound where the sonic event can still be heard

Acoustic Arena - A region where listeners are part of a community that shares an ability to hear a sonic event

Ambient sound - the background sounds not necessarily in the forefront of the sonic experience such as mechanical sounds from the building

Point Source Sound - Sound emanating from one source - related to acoustical footprint. In this case an example is the individual within a space. The individual's acoustical footprint is comprised of their own speaking voice, footstep, whistle, or clothing noise (influenced by the physical space that they are inhabiting). 
Acoustic Projected Source Sound - Sound emanating from a specific acoustical object designed with the objective of projecting its range. In the Ogilvy building the primary acoustic projected sound sources are musical instrument or musical event.

Amplified Projected Source Sound - Similar to an Acoustic Projected Source Sound, but, regulated electronically through amplification. In doing so the volume of the projection can be controlled and the original source of the sound can vary from its projection point 


\section{Introduction}

One of the most important and primal senses in understanding the world is that of audition. From a scientific perspective sound objectively exists as waves or pressure emitted by a source in the atmosphere, perceived through vibrations in the ear, and transmitted as sound to the brain. ${ }^{2}$ The nature of hearing and perception is very subjective. What one may perceive as positive sound another may deem as utterly intolerable or even as noise. Noise can be defined in a variety of ways, the most common of these being "unwanted sound". But what characteristics must a sound embody in order to be deemed unwanted? One definition revolves around the idea of control, or lack thereof, in the experience of sound; whereas the listener is at the mercy of a sound or noise that negatively impacts them. This is one way to define that, but still there are others that say noise is any sound that is loud or unpleasant and causes a disturbance. This definition however leaves much to subjective interpretation. There are various factors that influence how a sound is experienced, how it is subjectively perceived, and the physical result of its impact on the listener.

The intrinsic non-tangible properties of sound have resulted in a variety of representations, the majority of which are visual in form. Understanding sound visually and relying on the sense of sight has become the standard form of illustration, due partly to the visual (sense) dominance in modern society and its ability to capture a phenomena through a al representation such as art and, in theory, sustain it indefinitely within its physical parameters. Furthermore, the ability to 'record' sound and reproduce it did not exist prior to the development of the phono-

2 Christopher N. Brooks, Architectural Acoustics (Jefferson: McFarland \& Company, Inc, Publishers, 2003).

3 Garret Keizer, The Unwanted Sound of Evervthing We Want (New York: Public Affairs Perseus Press, 2010). 15

4 Keizer, 24. 
graph during the late $19^{\text {th }}$ century. This is because of the transitory nature of the medium of sound versus that of the visual arts, whereas the materials within the visual arts have a much greater sense of permanency than those of sound waves. These visual interpretations and representations become a way of measuring sound in a different quantifiable way (no longer decibels and frequency). Whether it is sound embodied through the visual arts, literature, poetry, or notated/performed music, all provide a basis for a greater understanding of how sound can be experienced.

Architecture also provides a means by which sound can be expressed and interpolated, as it is a inhabitable space possessing sonic properties. Similar to the way in which the visual arts are used to depict and understand sound, there exists the possibility to create the notion of sound through architectural representation (notated and build).. Whether consciously or not, the creation of space is always the creation of sound for there is always sound occupying space.

To discuss sound poses several difficulties due to its very fleeting nature. Sound is most visible, and arguably becomes visible, only through its effects on the surrounding environment. Similar to how we perceive wind by witnessing rustling leaves on a tree, sound can be seen by the effect that it has on various entities. Before one can begin to understand and discuss the nature of sound and its causality, it is helpful to first define and categorize sound based upon its attributes and uses.. However, these attempts present their own myriad of complexities due to the subjective nature, as well as the role of individual perception, in understanding sound. It is beneficial to parse the parameters of sound in order to develop a successful architectural sonic design process. 
Architecture is the sum of intricate cultural, physical, and social constructs, each of which has a unique relationship to sound and noise. Sound is embodied and represented in a multitude of ways, most of which are up for subjective interpretation. It is without doubt that all architectural space encompasses sound; where further definition is needed is in qualifying the sounds that we are hearing and in directing their interactions. As previously mentioned, one of the most common definitions of sound is noise. The term has generally come to refer to negative sounds that cannot be controlled as they are experienced by a listener. Whether it is organic, mechanical, or environmental, the prevalence of noise in everyday life cannot be disputed. Before it is possible to investigate the various ways that architecture can shape sound and negate noise, it is instructive to first explore the various facets that sound and noise exist in (not solely within the realm of architecture).

Representations of sound and noise have been explored in a multitude of ways. From the avant-garde's simultaneous poetry to Jack Kerouac's onomatopoetic verse, the phonic properties of the written and spoken word are manipulated in order to convey certain emotions and notions. In addition, aspects of the Futurists' various manifestos highlight the re-evaluation of the sonic world, and as a result, the birth of a new noise and aural representation of society. They demonstrate the profound impact that noise and sound have within a society, and highlight the need to place greater emphasis on their creation and understanding.

Composer and architect Iannis Xenakis explored the relationship between music and space in his numerous musical compositions. He directly addresses the issue of sound within architecture through the sound space of the Philips Pavilion. As part of the 1958 Brussels World Fair, the pavilion was a specifically designed space which combined the visual, spatial and sonic together creating a holistic architectural experience. 
This thesis will utilize the knowledge of sound representation and interpretation within the arts and music and apply it directly to architectural design.

A contemporary paradigm of sonic experience is the shopping centre - a sonic (and spatial) environment that encapsulates the social, cultural, physiological, and visual components of sound experience. The shopping centre or mall has a history based in economic prosperity and has developed its own culture around fiscal success and societal presence. The experience of the space is a by-product of decades of evolution based ultimately on the bottom line of revenue. As a result, the disruptive cacophony of the space has become a place of disdain, creating a conflict between the modern cultural purpose of the mall as social gathering space and that of primarily an economic centre. This thesis will demonstrate that through understanding sound representation as a way of informing architectural design there exists the capability of defining and shaping/creating the aural spatial experience. In doing so, the resulting designed architectural space will integrate the sonic dimension intrinsically. Through investigation into the history, representation, and effects of sound, a comprehensive understanding can be applied to redefine the space of the mall as a beneficially sonorous experience, making it possible to venture away from the currently established view of its noisy condition. The site for such an exploration is the historic Ogilvy Building located in Ottawa, adjacent to the existing Rideau Centre Mall.

In a soundless room, the void of silence becomes filled by the overwhelming sound and awareness of one's beating heart. Noise impacts negatively on the psychology, physiology, social, and political wellbeing of a society. Within any given society, on any given day, the individual person inhabits, even if for only seconds, a countless number of different spaces, the majority of which have little or no regard to aurality, in terms of how they

5 Garret Keizer, The Unwanted Sound of Everything We Want (New York: Public Affaris Perseus Press, 2010). 
have been conceived and designed. The pragmatic course that architecture has taken disregards the design of a sound space and allows it to remain an unknown variable until a building's completion. Where the challenge lies, is in how to create a pleasurable aural space for its inhabitants where the soundscape is not a by-product but a specifically designed element. The shopping mall is a prime candidate in exemplifying these possibilities. Whereas a concert hall is a specifically designed space focused primarily upon the sonic condition, the mall is a real-life space with a wide range of uses and a large cultural impact. The established sonic environment is an afterthought and the result of design objectives which do not account for aural experience. Any aural design is merely a superficial intervention in the absorption/elimination of sound.

Through examining these notions and the theoretical implications of sound coupled with a sonically focused reconfiguration of the shopping mall, a higher-level understanding of the impact of sound within all realms including architecture can be achieved. 


\title{
Part 1: The Sonic Boom and the ever-
}

\section{happening cacophony of noise:}

\author{
the physiological, psychological, and cultural effects of
}

\section{clatter.}

A preamble on Noise

The advent of noise has close ties to the industrial revolution and modernity. Over the last century there has been much inquiry into the effects of excess sound and noise on the human being, both physically and mentally. By highlighting these effects, furthers the argument for the need to sonically reconfigure architecture. The effects of noise will be looked at from the physiological, psychological, and cultural viewpoints. This investigation will demonstrate the impact that sound and noise have within all aspects of life, and therefore, why it should be a prime concern within architectural design.

\section{Physiological}

Sound pressure waves have a profound effect on the human body. Such an effect can be witnessed by the presence of Infrasound and whole body vibrations. Defined as, "sound lower than $20 \mathrm{hz}$, or cycles per minute" infrasound has been known to impact the body in various negative ways. While research into infrasound effects is still at a preliminary stage researchers in Portugal and Germany have done studies on vibroacoustic disease.' The symptoms include "abdominal pain, chest pain, lump in the throat, urge to urinate and change in breathing

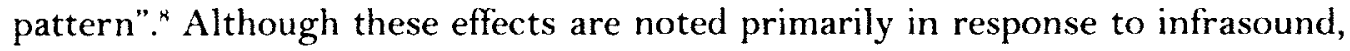
high frequency sounds also have great physiological effects on the body, as well as

6 Wikinedia_Infrasound, March 2012 <http://en.wikipedia.org/wiki/Infrasound>.

7 Keizer, 222.

8 Keizer, 229. 
those at a higher decibel level. Anxiety, high blood pressure, exhaustion and hearing loss are symptoms well documented in conjunction with excessive exposure to loud noises. A study that followed 10,872 sawmill workers in British Columbia over the course of 8 years concluded that there was a significant increase in hypertension for workers exposed to sounds 85 decibels or louder." Another study investigating Austrian schoolchildren showed that "those living in noisier areas exhibited elevated resting systolic blood pressure."'0

An attempt to quantify the effects of noise damage was conducted in the Netherlands through the development of the DALY, or disability-adjusted life year." To summarize, a DALY is equal to a year of lost life with various disabling conditions assigned a numerical weight; for instance, two years living with cancer is equated to one year's loss of life. Moreover, a monetary value is assigned to the amount that people are willing to pay in order to lower their risk of dying, this amount varies from country to country. For example, in an average European country the cost is roughly $70000-80000$ Euros. Referenced with noise and sound related ailments in terms of DALY's, noise costs the Netherlands about 38 o0o Daly's per year. ${ }^{12}$ Therefore, the effects of sound induced ailments such as heart-loss, hypertension, and high blood pressure can be equated to a corresponding DALY amount. For example, if 2 years living with cancer is equal to losing one-year of life, then perhaps, 5 years living under stressful sonic conditions resulting in high blood pressure is also equal to losing one-year of life.

\section{Psuchological}

While noise has direct physical effects on the human body, arguably, more severe and hindering are the psychological effects. A prime example of this comes in the form of sound torture, either through the means of a) using 9 Keizer, 33.

$10 \quad$ Keizer 38

11 Keizer, 196.

12 Keizer, 136 
noise, or b) using an absence of noise (silence).$^{19} \mathrm{~A}$ space that exemplifies both of these is a prison where extreme noise and extended durations of silence cause great psychological damage. To put this in perspective, the Environmental Protection Agency recommends that the standard noise limit in school classrooms fall between $35-40$ decibels. In contrast, the American Correctional Association limits daytime prison noise to 70 decibels, which translates to being $10 \mathrm{x}$ as loud. (For every 10 decibels change, the perceived loudness is double, therefore, an increase of 35 decibels equates to approximately $10 \mathrm{x}$ as loud).${ }^{17}$ In contrast, solitary confinement, and extended periods of silence separated from social interaction can cause the same amount of damage as a severe head injury. ${ }^{15}$ Garret Keizer goes insofar as to hypothesis that the sonic condition within a prison contributes to a hindrance in the intended rehabilitation of the prison system itself. Not every person incarcerated is a hardened criminal, but the prison system itself, and more specifically the sound environment, creates a hardened person by the end of a sentence. ${ }^{16}$ He continues this notion and suggests that perhaps a sonic-evaluation of those criminals' sonic upbringing could potentially highlight the influence on noise/sound in shaping their character traits and elements of their personality.

\section{Cultural}

The cultural effects of noise are less apparent than those accredited to psychological and physiological damage. Cultural effects can be observed on a more subtle level, particularly in the inverse relationship between socioeconomic class and noise. It has been well documented that where there are elevated noise levels, generally, there is a tendency towards higher levels of aggression and violence. ${ }^{17}$ Furthermore, where there is noise there is instability and learning difficulties. ${ }^{1 *}$ So, should one find it shocking that lower-income

Keizer, 126.

Keizer, 178.

Keizer, 177

Keizer, 179.

Keizer, 202.

Keizer, 124. 
neighbourhoods are often situated in noisy conditions such as adjacent to an airport? ${ }^{19}$

Studies have been conducted by various institutions that demonstrate a direct relationship between income and noise exposure. A British survey found that "One in five people with incomes of less than 17,499 Pounds annually regularly heard noise from neighbors; one in eight for those making over 30, o0o Pounds annually. Those in social housing fared the worst with 93 percent regularly hearing noise from neighbors." ${ }^{\circ}$. In 2004 in upstate New York a study of 9-11 year olds from 216 , predominately Caucasian low and middle class families, were studied on factors such as overcrowding, noise, and housing quality. It was concluded that five times as many low-income children as middle -class children were exposed to two or more environmental risk factors which directly affected and were related to overnight urinary neuroendocrine levels, which indicates chronic stress (largely in part to noise). ${ }^{21}$ This suggests that further attention to areas of human life, such as housing, needs to be addressed from sonic perspective. Moreover, attention to programs which do not seem to have sound as the principal character of a space are very much needed.

19 Keizer, 145.

20 Keizer, 55.

21 Keizer, 56. 


\title{
Part 2: Did you see that? It was loud!
}

\author{
Did you see that? It was so loud! - Sound \\ interpretation from Russolo and the Futurists, to the avant- \\ garde poet, to Nono, Xenakis and Byrne.
}

The visual arts provide the opportunity for sound to be explored within this comfortable and well-versed medium. By relying on the sense of sight, which has become the primary mode of understanding in Western Culture, sound representation within the visual arts creates a common language.

Sound is a very intangible element in terms of visual understanding. It can be measured in frequency, waves, pressure and so forth and notated numerically; but it is very difficult to capture and to translate it to the visual medium. The reason for this is because once sound is personified visually, as within art, it moves away from its original sonic state and away from the intended auditory sense. When recounting a sonic experience description is most successfully achieved through the use of linguistic metaphor. Words have the capability to strongly infer a sonic understanding. For example, one can say it was loud, quiet, high pitched, bassy, and so forth. However, although these physical sound attributes may be accurate the meaning of the sound becomes lost. For example, at the climax of Beethoven's Fifth symphony there is a sound easily recognizable to most that - if you were to translate into words referring only to its physical properties - would be described as: loud, of harmonious frequencies, resonating, and of dynamic timbre. However, a more sensible recounting of the event would use words and phrases such as, "at the climax it was so thunderous and full of passion, like a stampede of horses running for survival through a rich oasis. The music had an intense anger and determination; I was on the edge of my seat with anticipation." In such a recounting a better understanding of the music is evident; however, how is it possible for sound waves and frequencies to 
be angry, thunderous, or passionate? We understand the message coming across but in reality these are not values and quantities that are associated with sound, and yet we still assign these attributes to them. If one was asked to create a visual representation of the same excerpt of music using non-verbal or linguistic devices, for example only color, what would the results of such an experiment be? Sound waves may lack the ability to be angry or thunderous; however, it is quite possible to create a visual artistic representation with these qualities.

It is through various representations that a listener further understands the sounds they are hearing. Such representations are achieved through linguistic frivolity or visual artistic means. This is where the interdisciplinary cross over between the visual and the aural sense exists. How is something non-tangible like sound represented in something so utterly tangible as literature, painting, or the built form? Understanding the representation of sound provides insight into a multitude of academic queries, and also contributes to the understanding of space.

There have been many crucial movements, as well as individuals, that have specifically highlighted sonic representation: The Futurists, the Avant-gardes poet, and Iannis Xenakis.

The area of the audioception offers the possibility for space and sound to be more holistically explored, as demonstrated by the Futurist movement which originated in Italy shortly after the turn of the century. The influence of The Futurists in informing architectural design is evident in the push from a purely static visual representation to a multi-faceted dynamic association, where the individual becomes a critical component.

For the purposes of this query focus will be placed on The Futurists' manifesto, primarily Russolo's Art of Noises. The Futurist movement also had a strong political and social agenda; however, this will not be the focus for exploration. 
Shortly after the turn of the century, during the Industrial Revolution, Europe was undergoing a great cultural change; some of the most prominent figures who played a role in this cultural shift were The Futurists. As a collective whole they strove to revamp the way the world was experienced and artistically expressed. Drawn to the beauty of the machine and the harmonious mechanical functioning of the industrial world, The Futurists put forth several manifestos in an attempt to categorize and establish their goals, thoughts, and ambitions. As outlined in Russolo's Art of Noise, a large emphasis is placed on sound and noise as a key element of inspiration.

\section{The Futurists: From a Sonic Perspective}

The Futurist movement acted in opposition to many established artistic and social movements. Deemed as the father of Futurism, Marinetti's Futurist Manifesto outlined in a poetic nature the basis of the futurist way of thinking. By turning away from the traditional artistic and social ideals he opened the door to a series of thoughts and ideas limited by no restriction. This is not to say, however, that all aspects of the Futurist movement were of higher intellectual thought or extremely profound. Despite this, by redefining what was considered normal and viewing the world in a different way, it turned conventional thoughts of art, music, society, and culture upside down. Regardless of the outcome it opened the door for the re-evaluation of many important and critical elements (in this case it is the reinvention of music and the evolution of the definition of noise).

Soon after Marinetti published his Manifesto, artist and painter Luigi Russolo published his own manifesto in the form of a letter addressed to Marinetti. Russolo's manifesto entitled "The Art of Noises" focuses on the aurality of the futurist world and how one must re-examine the sonic events within it. He draws strong connections between machinery, and in particular the machinery of war as a source of inspiration for this new acoustic world. 
What the Futurists accomplished through their various manifestos, in particular The trt of Noises, was a re-invention in the way we think about noise and sound in terms of notation, production, and cultural experience. Russolo created something completely new and unique - not only original pieces of music and startling compositions, but as well, reinvented music and composition all together by creating and re-defining the contributing parts (i.e. the sounds themselves). Instead of relying on a set of pre-established and antiquated notes and chords he strove to create something innovative in order to draw emphasis to the intinite nature of sound-composition, thus broadening the modern day definition of music. He accomplished this through the development and creation of his noise intoners as pictured in figure 3.

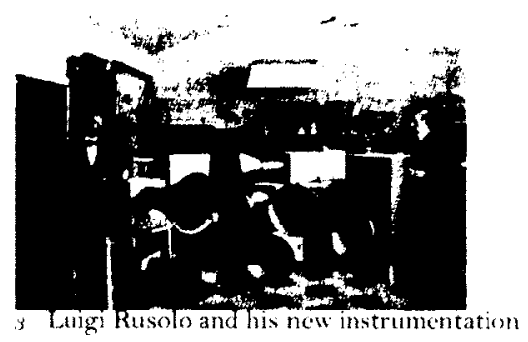

This mentality of reinvention parallels similar issues that have arisen in architecture. The established and pragmatic way of architectural design/ construction, despite being successful, imposes limitations on one's ability to think creatively and outside the confines of convention. This thesis looks at the problems surrounding designed acoustic space, and the incorporation of aurality into architecture as an integral part of its materiality. In order for the issues to be properly addressed aspects of 'The Futurists' philosophy can be drawn upon, and start with a blank canvas when approaching the examination of architectural space in conjuncture with sound. The Futurists deconstructed the preconceived notions of their generation that surrounded musical sounds, as well as tracing their origins and development throughout history. Russolo acknowledged the status quo of musical composition, and in turn created a new musical rocabulary and genre that he believed to be more indicative of the newly industrialized culture. If we approach the current shopping centre as a 
our contemporary status-quo, then it too would benefit from the application of Russolo's ideologies.

\section{Russolo's Art of Noises 1913}

In the The Art of Noises, Russolo comments on the current sonic understanding of the world, the urbanized-industrial society, and the accompanying musical score. Russolo begins by stating that prior to the industrial revolution noise did not exist, that "in antiquity, life was nothing but silence" ${ }^{2 z}$. He observed that even the loudest of noises were not intense or prolonged and dismissed nature as "being naturally silent". However, he excluded the sounds created by storms, hurricanes, and avalanches as exceptional telluric movements. While there may be truth in this exclusion, the scope of this assertion must be questioned when consideration is given to the fact that some of the most epic sonic events draw their origins from nature alone. Russolo continues through a brief history of the development of music, humanity's ability to make noise, and the divine associations of such a creation. He argued that because of this divine association the development of music had slowed in progress and became limited. He saw the musical palette as consisting of restricted intervals, musical sounds, and rhythms. Moreover, he asserted that music had reached a plateau where it "looked for soft and limpid purity of sound...intent upon caressing the ear with suave harmonies" ${ }^{2}$, and this pure sound "with its littleness and its monotony, not fails to arouse any emotion." Russolo's solution to this was to "Break at all cost from this restrictive circle of pure sound and conquer the infinite variety of noise-sounds"24. He acknowledged the past achievements of Beethoven and Wagner but notes that modern society had bored of the music of the classical masters and "This is why we get infinitely more pleasure imagining combinations of the sounds of trolleys, autos and other vehicles, and loud crowds, than listening once more, for instance to the heroic or pastoral

22 Luigi Russolo, The Art of Noises (Something Else Press, 1967).

23 Russolo, 5.

24 Russolo, 6. 
symphonies" ${ }^{\prime 2.5}$. He used such terms as anaemic sounds in reference to concert halls, and called for the re-examination of what it meant to create musical noise. To further his explanation he cited Marinetti's Orchestra of a great battle:

12345 seconds the siege canons gut the silence by a chordTamtoumb! Immediately echoes, echoes, echoes, all echoes-quick! take-it-crumble it-spread it-infinite distance to hell. In the center, center of these flattened TAMTOUMBS-width 50 square kilometersleap 2368 splinters-fisticuffs-headrammings-rapid fire batteries Violence, ferocity, regularity, pendulum game, fatalitythis grave bass apparent slowness-scan the strange madmen very young-very mad mad mad-very agitated altos of the battle Fury anguish breathless ears My ears open nasals! beware! such joy is yours o my people to sense see ear scenl drink everything everything everything taratatatata the machineguns shouting twisting under a thousand bites slaps traaktraak cudgellings whippings pic pac POUMTOUMB juggling clowns' jump in full sky height 200 meters it's the gunshooting Downwards guffaws of swamps laughter buffalos chariots stings prancing of horses ammunition-wagons flue flac zang chaak chaak rearings pirouettes patatraak bespatterings manesneighings i $i$ i $i$ i i i medley tinklings three bulgarian batallions on the move crook-craak (double bar slowly) Choumi Maritza o Karvavena officers' shouts copper plates knocking against each other pam ici (vite) pac over there BOUM-pam-pam-pam here there there farther all around very high look-out goddamnit on the head chaak marvelous! flames flames flames

flames flames flames

flames crawl from

forts over there Choukri Pacha telephone orders to 27 forts in turkish German hello Ibrahim! Rudolf hello! hello! actors roles blowing-echoes odor-hay-mud-manure I can't feel my frozen feet stale odor rotting gongs flutes clarinets pipes everywhere up down birds twitter beatitude shade greenness cipcip ip-zzip herds pastures dong-dong-dong-ding-bééé Orchestra Madmen keep hitting orchestra professors they bent beaten playing playing playing Great fracas far from erasing drink tiny noises revomit them precise them out of their echoing mouth wide open diameter 1 kilometer Debris of echos in this theater of laying rivers sitting villages standing mounts recognized in the audience Maritza Tungia Rodopes 1 st and $2 d$ rows loggias groundfloor boxes 2,000 shrapnels gesticulation explosion zang-toumb white handkerchiefs full of gold toumbtoumb clouds-gallery 2,000 grenades thundering applause Quick quick such enthusiasm pulling hair very black hairs ZANGTOUMB-

25 Russolo, 6. 
TOUMB war noises orchestra blown beneath a note

of silence hanging in full sky captive golden balloon controlling

the fire. ${ }^{26}$

He proposed a new futurist orchestra like no other, with an absence of all strings, brass, woodwinds, and expected instrumentation. To define this new aural quality he classified all sounds into 6 categories:

1. Roars, Claps, Falling water, Driving noises, Bellows

2. Whistles, Snores, Snorts

3. Whispers, Mutterings, Rustlings, Grumbles, Grunts, Gurgles

4. Shrill sounds, Cracks, Buzzing, Jingles, Shuffles

5. Percussive noises using metal, wood, skin, stone, baked earth, etc

6. Animal and human voices, shouts, moans, screams, laughter, rattling's, sobs

Russolo viewed all other noises as combinations of these.

He concluded that by coupling predetermined noises with existing or future mechanical processes it would be possible to create and manipulate these elements in order to compose a truly stimulating sound.. and in essence that every factory be turned into an intoxicating orchestra of noises.

Russolo started by categorizing sounds and then proceeded to arrange them into unheard orchestral pieces that have had a great impact on how the very common sonic event of musical performance is experienced. With architecture the various components that come together to create space can be similarly categorized and in turn reassembled to highlight a desired sonic environment that more accurately reflects cultural and societal needs. The types of sounds produced in the soundscape of the shopping mall can also be categorized and equated with a specific visual representation. These sounds then become the 
building blocks for the architectural composition of the space. By designing what sounds can exist and where, it is possible to suggest possible desired interactions. In the case of the shopping mall, an adaptable sonic space $e^{2-}$ that simultaneously functions as social gathering space as well as successful economic centre, the specific sound spaces will be erident despite the fact that it is not possible to physically see sounds.

\section{Music and architecture}

Born in Venice, Italy in 192.t, Nono was one of the most prominent and important composers of the $20^{\text {th }}$ century. He placed great emphasis not only on the notational space of music, but on how the production of sound and its projection within space was fundamental to the overall dramaturgy and sonic experience of his works. ${ }^{-1}$ This is best exemplified through his work Prometeo. Architect Renzo Piano played a vital role with his ark design for the performance space. The boat-shaped structure placed the musicians on balconies surrounding the audience on the ground level with various orientations. The works of Luigi Nono looked at reinterpreting how sound exists within a space, where each performance becomes a unique event tightly linked to the space in which it is performed, with emphasis on the aural experience more so than the visual. Nono, amongst other avant-garde composers such as Xenakis, demonstrated the power of musical composition and performance in shaping and manipulating the perception of the architectural space in which it was performed.

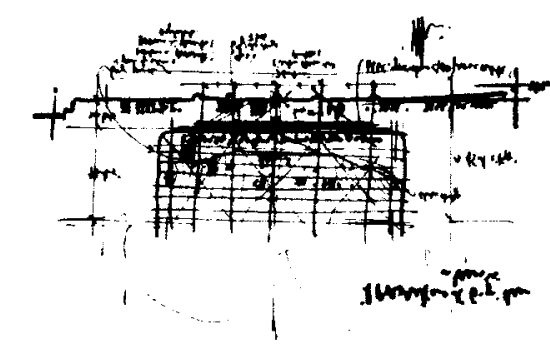

+ Renzo Piano. the Ark. Sketch and structure

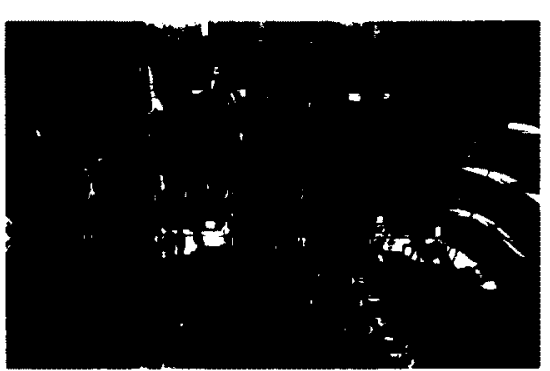

; Renzo Piano. the Ark. Structure 


\section{$\underline{\text { Xenakis }}$}

The overlapping and intricate connection between the visual representation of sound/music and the aural experience is best exemplified through the works of Iannis Xenakis. Born in Greece on May $29^{\text {th }}, 1922$, Xenakis later fled to France in 1947 where he worked as a composer, music theorist, and architect. His work intrinsically incorporates the visual representation of the score within the performance, and within space. He believed the primary difference between music and architecture was "that while space is viewable from all directions, music can only be experienced from one" ${ }^{\prime 9}$. He used intricate graphic notation to visually explain and represent his musical thought. Xenakis' first major work, Metastasis, was composed in 1953-54 and premiered at the Donaugeschingen Festival in 1955. The instrumentation included 61 musicians: 12 winds, 3 percussionists (playing 7 instruments), and 46 strings. Its basis was that, "Music usually consists of a set of sounds ordered in time; music played backwards is hardly recognizable" and with the goal to "reconcile the linear perception of music with a relativistic view of time". For example, in warfare it is impossible to identify the sound of an individual bullet being fired, however, the sound of gunfire is unmistakable. The sequence in which the guns were fired (in relation to time) becomes irrelevant; regardless of the pattern in which they were fired the sound produced and perceived is the same. This moves Metastasis away from the linear one dimensionality of music and allows the listener to begin to experience the composition outside the realm of time. A similar notion exists in architecture, where experience of a space is comprised of inputs from multiple senses at the same time, independent from time. The score for the piece (fig 9 ) resembles an architectural plan more so than musical notation. The spatiality within the notation is evident and translates to the sound space of the heard composition. $^{31}$

29 Wikipedia-Metastasis (Xenakis). July 2012. http://en.wikipedia.org/wiki/Metastasis_(Xenakis)

30 Wikipedia - Metastasis (Xenakis). July 2012.http://en.wikipedia.org/wiki/Metastasis_(Xenakis) 31 Although the performance of the piece itself does not necessarily include a physical spatial element, the Soundscape of the piece (from definition in glossary) invokes a sense of spatiality within time. While the musical experience may be linear, its perception (similar to architectural perception) is dynamic. 


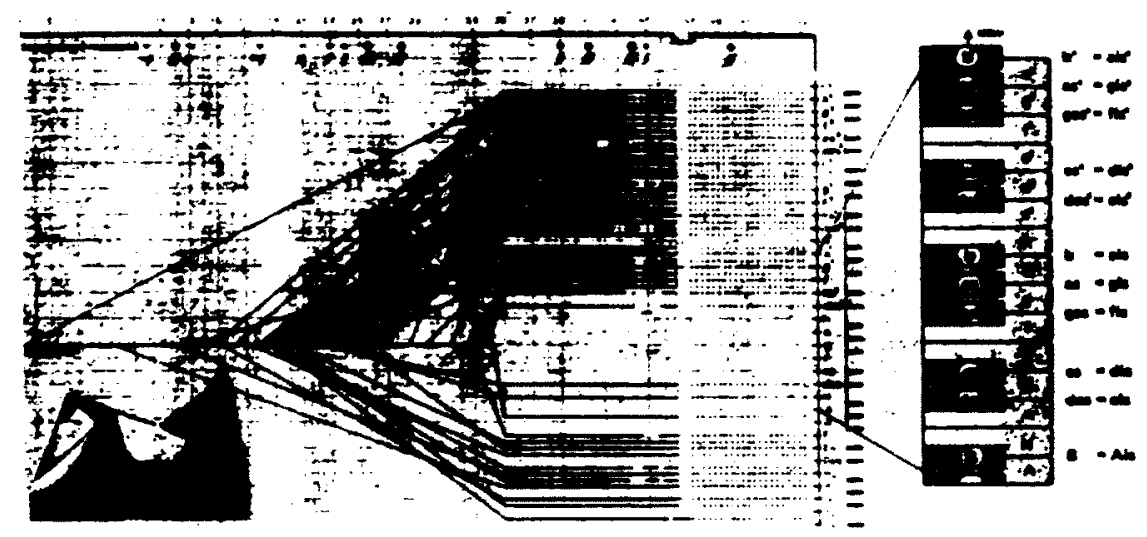

6 Xenakis: Metastasis Score

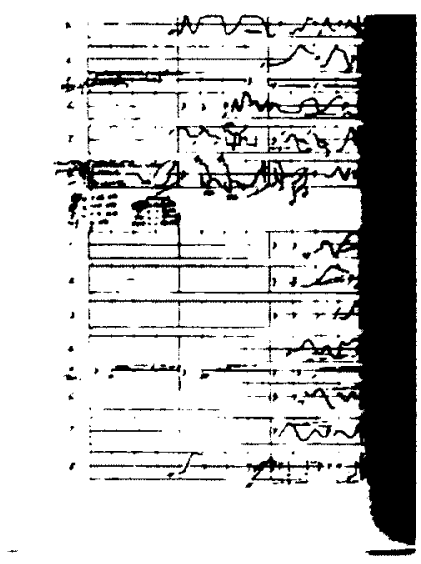

Xenakis: Musical Score

The idea of spatiality in composition is continued with Xenakis' composition Terretektorh which was composed in 1966. This composition takes the notion of spatiality within the score and extends it to the performance. It premiered at the Contemporary Music Festival in Royan and was composed for an 88 piece orchestra. The composition calls for the performers to be dispersed around and throughout the audience in a large circular cluster with the conductor at the centre. Xenakis described the piece as a "Sonotron: an accelerator of sonorous particles",32, where the sound moves around the audience in various ways. The opening sequence centers on a single note that is passed around the orchestra creating a swirling effect throughout the audience. As the piece continues wood blocks are used to create clapping sounds that again move throughout the audience. This spatial element is near impossible to create electronically without recording 88 individual tracks. The musical score/plan (fig. 8 ) for the piece shows swirls of sound clustered around the positions of the orchestra members and various instrumentation.

Xenakis is arguably most well known for his work on The Philips Pavilion which was designed for Expo' 58 in Brussels. The project was formally being completed by the office of Le Corbusier, but due to Corbusier's commitments in India it is widely agreed that the majority of the project was completed under the direction of Xenakis. It combines visual representation, poetry, spatial musical composition, and architecture to create a dynamic sonic space:

32 Xenakis Terretektorh. July 2012. http://www.answers.com/topic/terretektorh-for-88-musiciansscattered-among-the-audience 
a hyperbolic paraboloid spatialized by sound. The shape of the architecture is derived from the graphic notation from his early work Metastasis (refer to fig 9).

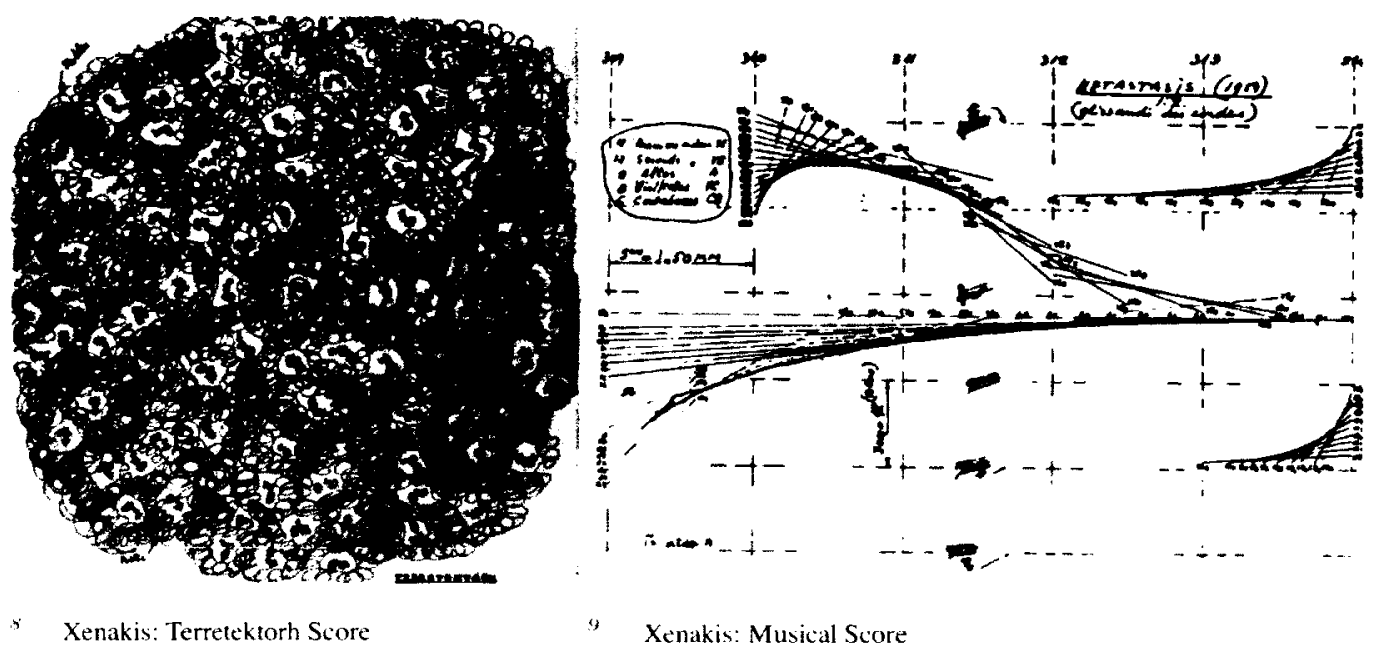

The pavilion was commissioned by the electronic company Philips, and was intended to celebrate postwar technological process. Inspiration for the pavilion came from Poeme Electronique, a piece of electronic music composed by Edgar Varese. Varese's score for Poeme Electronique details a specific momentby-moment breakdown, orchestrating the images to be projected around the musical score. The physical parameters of the structure were intrinsic to the experience as different thematic sections were projected in specific areas of the building, in relation to the origin of the sound, from the complex speaker system. There were seven themes: Genesis, Spirit and Matter, From Darkness to Dawn, Man- Made Gods, How Time Moulds Civilization, Harmony, and To all Man Kind. The higher level organization of the poem somewhat follows the growth of human civilization, paralleling the main objectives of the pavilion to celebrate human technical achievement.

The parilion itself was stomach-shaped in plan, meant to funnel people in and out of a larger cavernous space. The number of speakers is estimated to have been between $350-150$ around the entire space. The result was a space that one could occupy that was delineated by the physical parameters of the 
structure, the projected visual representation of the poem/composition, and the placement, directing, and creation of the sound space. Although on a lavish and shocking scale, these principles can be translated to contemporary functional architectural design. The Phillips Pavilion takes each to an extreme, and in doing so, draws attention to architectural experience - specifically its aurality.

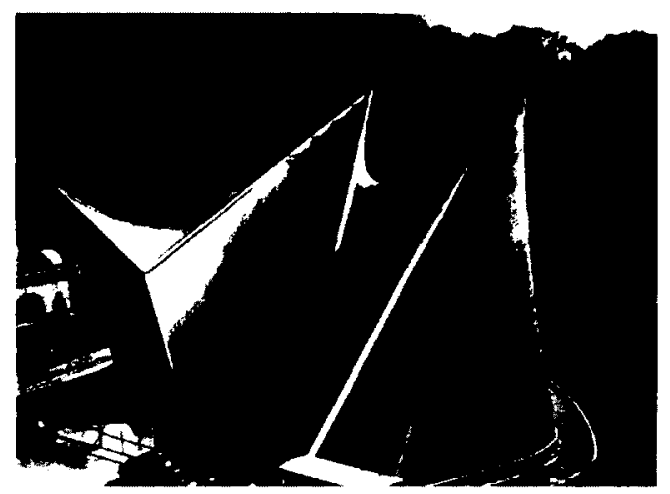

10 Philips Pavilion

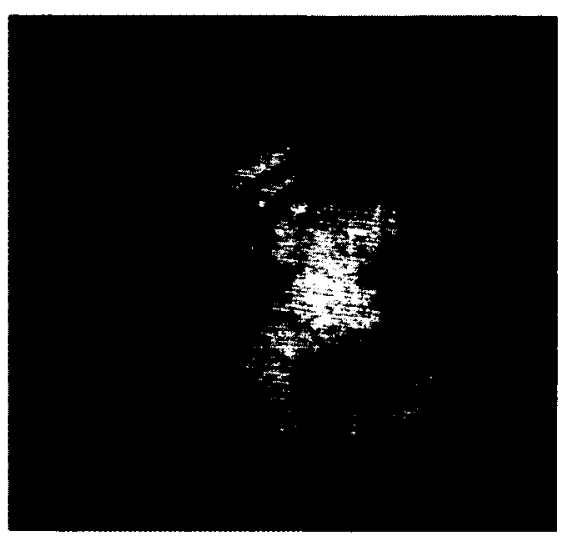

"I Philips Pavilion Image

\section{David Byrne}

There have been many installations that question the relationship between sound and architecture. The use of sound as a medium to explore architectural and spatial conditions is explored in the work of musician and artist David Byrne. He addresses the reciprocal relationship between architectural space and musical performance, questioning which influences which to a greater extent. In a $2010 \mathrm{TED}$ talk lecture, Byrne reviews the evolution of music style directly in conjunction to their accompanying performance venues ${ }^{3: 3}$. In doing so he highlights how the music style, timbre, rhythm and so forth, are perfectly suited to their performance venue. For example, with the move to larger concert halls and great reverb, the aural separation between performance and audience grew. The crowd was now silent, allowing the music to use greater dynamic range and less noticeable musical devices. Such a venue would not be ideal for loud electronically enhanced rock or pop music. It becomes evident that these architectural spaces interpolate the 
sounds that are performed within them, therefore greatly influencing and directing the way in which one listens.

One work of Byrne's, Playing the Building, moves the individual from observer to participant. "Playing the Building is a sound installation in which the infrastructure, the physical plant of the building, is converted into a giant musical instrument. Devices are attached to the building structure - to the metal beams and pillars, the heating pipes, the water pipes - and are used to make these things produce sound. The activations are of three types: wind, vibration, striking. The devices do not produce sound themselves, but they cause the building elements to vibrate, resonate, and oscillate so that the building itself becomes a very large musical instrument."

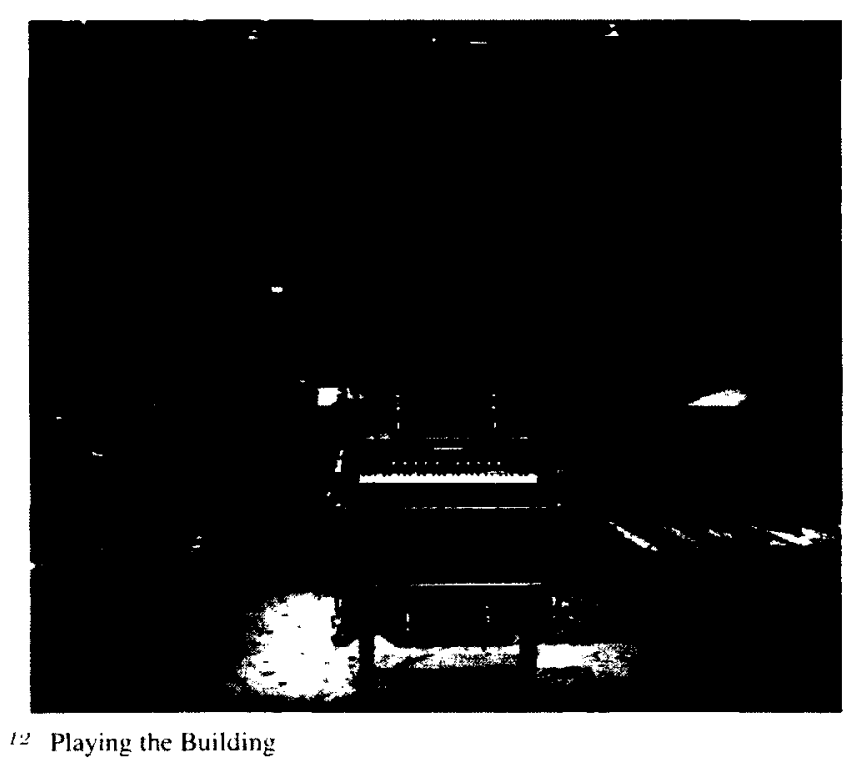

The sounds produced by the building are given temporal and spatial attributes that directly reflect their location and materiality. This in turn creates a unique sonic exp=erience for each listener dependent upon their location within the space, and if they are the listener or performer. In terms of reconfiguring architecture with emphasis on the sonic attributes (the shopping mall in this instance), it is reasonable to view the building as a sound installation art piece that also functions as a programmable space. Just as Darid Byrne utilizes the 34 Darid Byrne. David Byrne-Plasing the building, a) 12 , October $2011<$ http://wwwdavidbyrnecom/art/art_projects/playing_the_building/index.php>. 
built architectural form as a means of producing sound, one can use architecture to - if not directly through striking (as with Playing the Building) - manipulate sound. In the case of the re-imagined shopping mall there are various sonic sources including the users, and through strategic architectural intervention these sonic experiences can be adapted and manipulated in such a way that reflects the desired use and sonic environment of a space. 


\title{
Part 3: The Project Site
}

\author{
The Ogilvy Building and the Rideau Centre
}

\section{Elements within architecture:}

While the effects of material choices resonate throughout the architectural experience, their properties are quite fixed within a physical and visual understanding. Their sonic influence is also somewhat objective and well documented. For example, the acoustic effects of polished concrete floors versus that of heavy shag carpet is well understood from a purely physics perspective; the polished floor reflects sound waves where the carpet absorbs them.

The second element within architectural and spatial design is volume and proportion. These elements refer to the built form of the structure comprised of the various materials, i.e. where the walls, floor, and ceiling are. The plan/layout of these elements is crucial in the design, as it dictates not only the horizontal and vertical circulation within a space but also the overall plan.

The third element can be referred to as environmental or climatic. Perhaps not as important as proportion or materiality, it is still a contributing factor to the experience and perception of architectural space.

From these three somewhat simple elements one can move on to the more abstract, and arguably more important. The first of these elements is light. Whether it is artificial or natural, the way in which light enters a space is of great importance in shaping the feel of the space.

The last - and for the purposes of this thesis - most important, and frequently overlooked, is the element of sound. The importance and ramifications of sound/noise have already been discussed in some depth, so here we will focus primarily on the sonic properties of space. Through understanding how these various elements work together we will set the groundwork for the 
application of these principles in building design. Aural perceptual understanding is achieved through the orchestration of the various components within an architectural idea.

The most effective way to demonstrate this would be to review an existing piece of architecture. This examination will demonstrate how these architectural properties come together to create the existing aural environment. From there future designs will have this established understanding and be able to be successfully applied.

\section{Project Site:}

Located in Ottawa, Ontario at the corner of Nicholas Street and Rideau Street sits the opportunity to rethink the dichotomy of mall culture as economic centre and social gathering place. The most prominent shopping centre in the city of Ottawa is the Rideau Centre, which is located in the centre of the downtown core just moments away from Parliament Hill. Its location is somewhat contradictory to the contemporary suburban mall structure that has been adopted by much of North American society. Within the city of Ottawa itself this big-box suburban trend is demonstrated by the Bayshore, St. Laurent, and Westboro shopping centres. The Rideau Centre was constructed between 1981 and 1983 and required the demolition of an entire block of stores, some dating back to the turn of the century ${ }^{85 .}$. The location was a pre-established economic hub, due primarily to its convenient location adjacent to the By-ward Market and its close proximity to Centretown. Contradicting contemporary suburban mall structure once again the Rideau Centre is not simply a destination for shopping, as many other large North American malls, but has also become an important transportation hub; acting as a main thoroughfare between the Transit-way and Rideau Street. In addition, the Rideau Centre is connected to the prominent Westin Hotel, as well as the newly constructed Ottawa Convention Centre. Currently there are 171 stores distributed over 3 levels. 


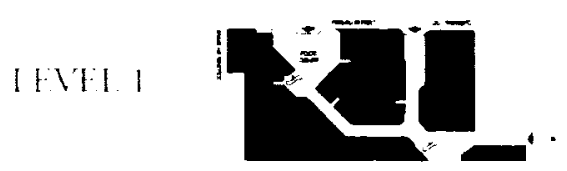

LEVEL 2

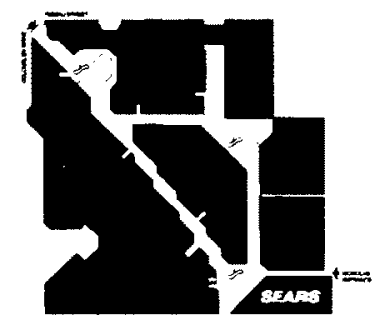

$1+$ Rideau Centre

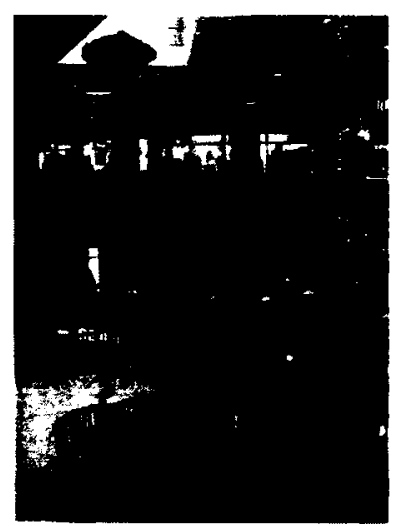

The interior layout is quite typical of the majority of shopping centres. It consists of wide corridors with many openings to the floors below and accompanying skylights. Vertical circulation is handled primarily by three major escalator systems. The plan allows large volumes of people to move through the space with relative ease - some bottle-necking occurs near the primary escalators. Sonically, the space is very animated and noisy. This is a result of the high rolume of people moving through the space with little or no physical separation within the corridors, as well as the independent soundtracks and sonic events spilling into the corridor from the stores. The materiality of the space also contributes to the sonic atmosphere with the use of hard polished surfaces and very little, if any, noise abatement materials.

Plans for the expansion of the Rideau Centre have been under development for the past decade, with most interest lying in the vacant parking lot directly to the East of the existing structure. The expansion has yet to be undertaken due to a number of negative variables, the most relevant pertaining to the Ogily Building's heritage designation. 


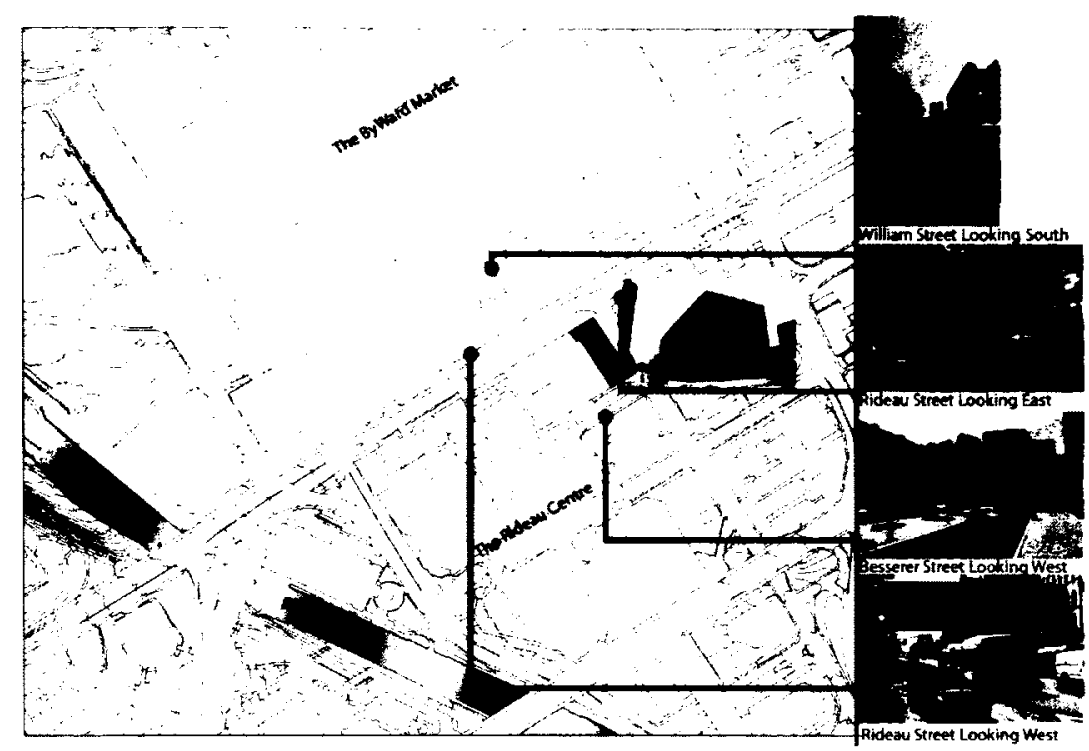

1: Site Plan. The location of the Ogilvy Building is indicated in red. The Rideau Centre is located directly South-West of the site and the Byward Market to the North.

Constructed in 1907 with further expansions taking place in 1917, 1931, and $1934^{36}$, the Ogilvy Building is an important piece of heritage architecture and is currently owned by the Viking-Rideau Corporation (owners and operators of the Rideau Centre). The first three levels (the original building) were designed by prominent Ottawa architect W.E Noftke, with the fourth and fifth levels designed by A.J Hazelgrove. The structure has been vacant for nearly twenty years as a result of a dispute over its heritage designation, and the push from the Viking-Rideau Corporation to demolish the structure and make room for the Rideau Centre expansion. In a 2006 report to the Local Architectural Conservation Advisory Committee and The Planning and Environment Committee a proposal was made to deconstruct the heritage facades and reassemble them after construction of the expansion. Its heritage value is found not only within its architectural design but also in its location, anchoring the end of an important block of Rideau Street.

36 Ned Lathrop, "APPLIC.ATION LNDER THE ONTARIO HERITAGE ACT FOR THE RECONSTRL CTION OF THE FACADES OF THE FORMER OGILV'S DEPARTMENT STORE AT Io6 RIDEAL' STREET," Application xslccall-template name="templ_prop_Comma"/> Local Architectural Conservation Advisory Committee, goot: 
As established within this thesis, the status-quo approach to mall design fails to achieve a positive sonic environment. However, the possibility exists to re-eraluate the sprawling big-box suburban mall and create an urban shopping district within the existing structure of the Ogilvy building. For this to be successful the previous stated knowledge of sound would be necessary. Through the in-depth theoretical investigation into the manifestations, understanding, effects, and theories behind sonic experience and sensory perception a new successful mall corridor can be achieved.
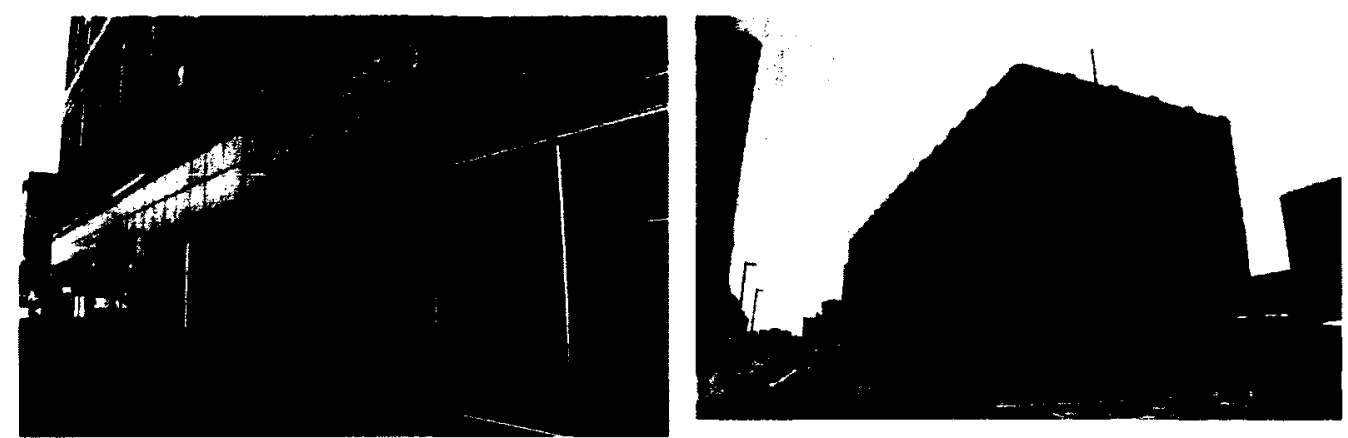

16. Ogilvy Building North facade detail 17 Ogilvy Building North East corner

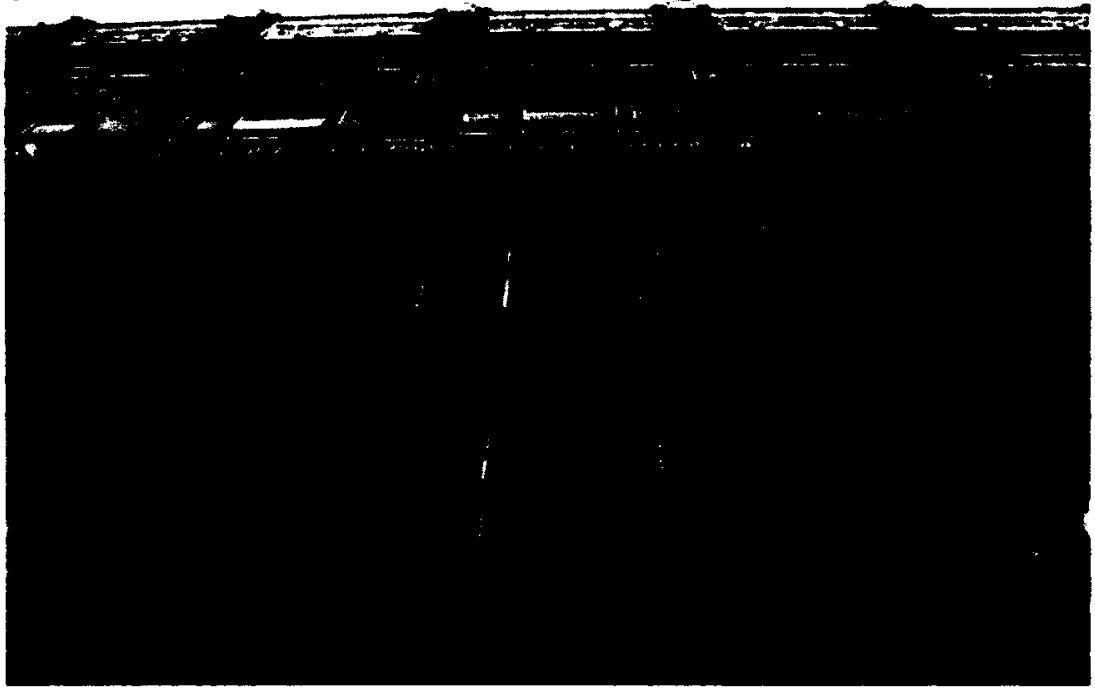

is Ogilvy Building East facade detail

19. Ogilvy Building South facade detail

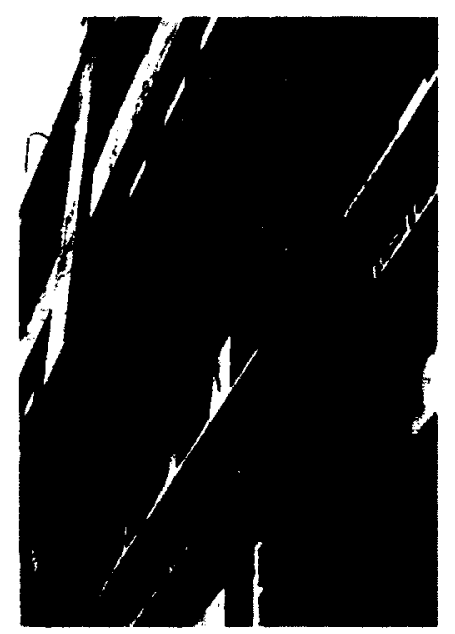




\section{Part 4: Dissecting the mall}

There are many places and events with unique and interesting sonorous attributes; one of the most troubled as previously discussed is that of the mall experience. Note that it is not simply the mall itself that is being analyzed here, the simple physical structure comprised of walls, ceilings, and floors, but it is the experience of it that is also being examined. The mall is a series of elements that together create the concept of the mall. The majority of modern malls have manifested as a series of boutiques strung together by an often confusing and loud series of corridors. In order to understand the spatio-acoustic environment of the modern shopping mall, it is helpful to consider the constituent elements that make up the mall. By doing so, it can be seen as not a single entity, but a complex web of associations, causalities, and unpredictabilities.

The design of the enclosed shopping mall dates back to of the end of the nineteenth century with the Cleveland Arcade, and since then the contemporary shopping mall has continued to grow at staggering rate. The shopping mall infers that there is a void in our lives and it can be filled by what is found at the mall ${ }^{s 8}$, playing on the need and greed of the general population. Malls have been designed to be the embodiment of "the good life" from the standpoint of late capitalistic society. The success of the modern day mall stems from the effective psychological manipulation of its patrons. By designing a place filled with abundance and removed from poverty, the mall develops the image of prosperity and success. Ruban Stahl developed the first mega-mall in the 1980's with 111 eateries, 836 stores, a wave pool, and amusement rides in West Edmonton. The idea was the longer you keep the average person in the mall, the greater amount of money they would spend. But alas, as one could assume, such a rate of growth is not sustainable. The world's biggest mall built in 1976, Randall Park, now sits empty and closed. In the 1970's and 80's in North America a new mall opened 
every three-four days. ${ }^{3 !}$ They were the most popular and profitable suburban destinations and their designs borrowed elements from churches." The use of water, light, and airiness, coupled with the humbling size, all contributed to creating these go-to places of economic and social worship. The entire basis for the mall comes from the desire for self-satisfaction.

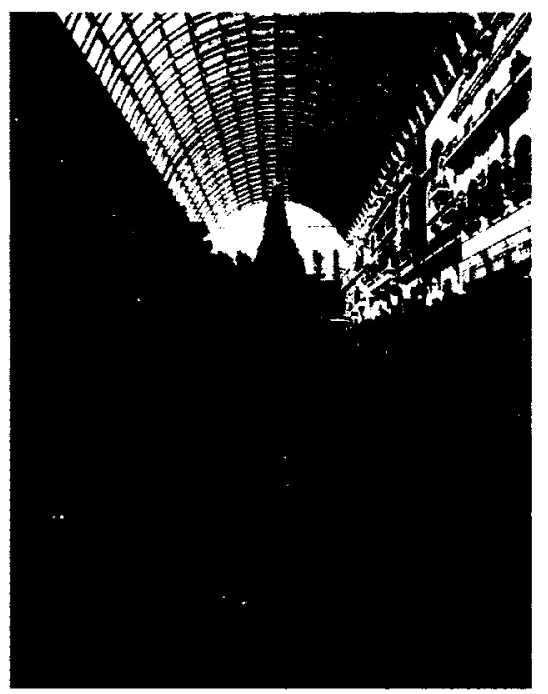

20 West Edmonton Mall

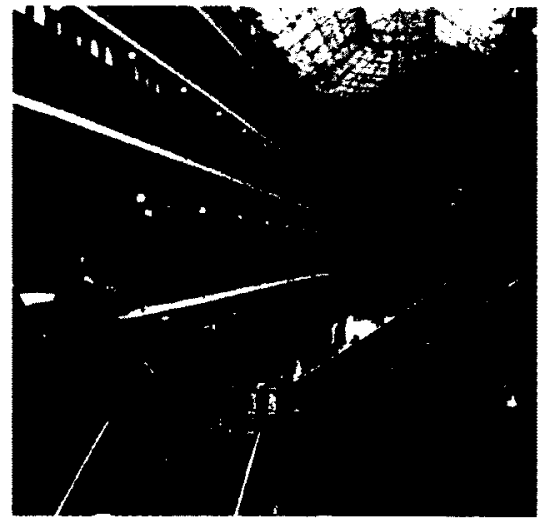

21 Cleveland Arcade

With the decline in North America mall-culture developers set their sights East into untapped territory. Some of the world's largest and most elaborate malls have been built in India and Dubai, several occupying a space equal to 370 football fields combined; the grow th of the mall in the East is unprecedented ${ }^{+1}$.

At the macro level there are several key elements that comprise the mall. In this chapter each will be examined to determine the range of their influence and contribution to the mall experience, their ultimate role in shaping the aurality of the mall, and their direct and indirect contribution to the creation of sonic events.

39 Jalls RLis dir. Helene Klodawsky, Larus Films, 2009.
40
41 
The most obvious element of the mall is retail, or more specifically, money and the culture of spending. It stands to reason that the economic forces that determine a mall's prosperity play an important role (buildings cost money). It is necessary to broaden our way of thinking and step away from the preconceived notion of the mall as a shopping centre. Think of the mall as a plaza or a square, or more specifically, the pedestrian mall. The most important and dominant factor in the mall is the person wandering through the space. For the sake of this diagnostic the mall visitors can be divided into two categories, the individual and the people (masses). The review of the mall experience can be, and needs to be, examined from both perspectives. What are the needs and wants of an individual, and how does that person contribute to the atmosphere of the space? A collection of people again can be considered one entity in its contribution to the sonic environment. The easiest way to differentiate between the two is to draw upon the architectural conditions within the built structure of the mall. There are two main components to the mall - the stores, and the spaces in-between; which are comprised of the corridors, open spaces and so forth. Once an individual crosses the threshold into a specific store they have in essence left the realm of the "mall" and entered the completely different space of the boutique. In this space, the individual, and more specifically their wallet, are of the utmost importance. The store is designed in such a way as to elicit the highest potential incoming cash-flow. The space opposite the threshold is the corridor whose sense of ambiguity is its most interesting quality. From a sonic perspective it is the masses in the corridors that are the primary source of sound. The mumble of separate conversations and people walking creates what's known as ambient noise. Anyone who has been to a modern shopping centre is privy to this sound and the way that it fills the space - often described as noisy and uncomfortable. Paralleling the noise of the people is the contrived and intentional noise of the mall, be it the mechanical system, escalators, or music being played over hidden loudspeakers. What happens if the sonic event of the masses is removed? The abandoned and silent mall is just as unnerving as the hectic noise and crowds of 
the day. This contrast further demonstrates the need for a sonic revamping, as is the case with some malls the corridors remain open for longer periods of time than the stores.

A significant contributor to the chronic noisy atmosphere of the mall is the Muzak being broadcast throughout the corridors and stores. Introduced in the 1930's it was discovered that by implementing pre-recorded music of particular tempos and energy into the mall space the shopping and purchasing patterns of the public could be manipulated. ${ }^{12}$ For example, the tempo of a piece of music is directly related to how quickly someone moves through the store. In contemporary times this may seem obvious, that fast upbeat music would result in someone moving with more urgency, as opposed to soft tranquil music slowing someone down. Similar to sound proofing interventions, such as acoustical foam or heavy drapery, Muzak acts like an air freshener, simply disguising the poor acoustic quality of the space and adding yet another complex sonic layer to an already disastrous and noisy situation.

It has been established that visitors, both individuals and masses of people, are a crucial element in the mall experience. If we focus on the relationships between the different users within this system, it is the social elements of the mall that become of interest. In the ambient noise of crowds that permeates the mall corridors, what are those people talking about? Why did they go to the mall to begin with? What percentage of the hundreds of thousands of people who visit the Rideau Centre in Ottawa, Ontario every year do so with the intent of purchasing something? And of those who made a purchase unintentionally, what was it that compelled them to spend? This is where the idea of the mall as a plaza and more than a simple retail outlet becomes evident. Within the mall there exists a diverse demographic of people, and depending on geographic location this diversity can vary. For example, malls situated in dense urban centers are more likely to attract a wider range of people given that the surrounding area is com- 
prised of people of varying socio-economic class. In contrast, take a mall situated within a suburb where the majority of the surrounding area is comprised of people who shares a common lifestyle. Regardless of the gap in diversity the mall is an exemplar of a complex social system. The context of the mall within a city or society has many implications. They have the ability to act as defining cultural elements for many cities. For instance, if someone mentions the Eaton Centre it evokes an image of the downtown hustle and bustle of Toronto. SoHo, NY is another example of a mall, in a more liberal sense, where the physical restrictions of the mall experience are the surrounding buildings and city blocks, opposed to walls and ceilings. West Edmonton Mall, the world's first supermall, is an iconic world-renowned symbol for the city of Edmonton. The social dynamic around and within malls is what makes the mall much more than a simply built space.

After taking into consideration the impact of the visitor in the mall experience the next point of investigation is in their governing - specifically the politics that surround the mall as an economic hub. Without a doubt the political factors in the mall experience are abundant. The construction of a mall can, and usually does, change the shape of a city tremendously. It lies in the political power of a jurisdiction that allows or disallows such development. For example, before the Rideau Centre existed there was another mall nearby; Sparks Street Mall. With the opening of the Rideau Centre the mall experience of Sparks Street was destroyed. More recently in April 2011, the new Convention Centre was completed in Ottawa directly adjacent to the Rideau Shopping Centre. The political influence on the mall reverts back to the original notion of the mall as an economic space. The modern day mall takes on the identity of the shopping centre or economic centre. Not only does it bring in revenue for the city and governing bodies via taxes and tourism, but it also provides employment for hundreds of individuals from sales associates and maintenance to administration.

The question is asked, "So what?" And the answer is found in the query, "Does the modern day mall work?" From the perspective of economic success the 
answer is easily obtainable from bank statements; however, from the viewpoint of individual experience and aural atmosphere the answer is no. In addition, should the aural atmosphere of the space improve it is safe to assume that the economic success of the centre would also benefit. The programmatic elements of the mall are fairly easy to outline as well as the contributing social, economic, and sonic factors - it is how they are brought together where it falls short. The number of required boutiques, restrooms, dining options, circulation elements, parking, and so forth, is easily outlined. Through this thesis the mall is to be used as a means of demonstrating aural design - placing aurality as a top priority in design, and inversely, how one can design for sound - by rearranging the elements of the mall experience in such a way as to design for aural space. 


\section{Part 5: Reassembling the sonic}

\section{corridor as a musical composition.}

The heritage Ogilvy Building in downtown Ottawa

The intended functional program is to parallel that of the contemporary mall, however, reinterpreted in a more cultural and dynamic method.

The proposed new mall within the Ogilvy Building

While the majority of space will be for retail sales, the nature of these spaces is geared towards independently owned smaller boutiques (approximately 700 square feet) similar to those that can be found on street-front shopping districts such as the Glebe, Westboro, and the ByWard Market areas of Ottawa. The location of the Ogilvy Building caters to a high volume of pedestrian foot traffic allowing for a wide variety of potential boutiques, smaller gallery spaces, performance spaces or specialty stores. The building is to be an extension of the streetscape, inviting a wide diversity of individuals.

Adaptable partitions allow for a wide range of store sizes and functions depending on current demand, and a varying degree of integration or separation from adjacent spaces. The end result will be a dynamic sonorous atmosphere with the capability of adjusting it to the user's needs.

The corridors will be delineated by the arrangement of the partitions, creating an organic layout that reflects the needs and use of the space. For example, during the busy season permeability into the space may be more open to accommodate larger numbers of people. In contrast, when sales slow the partitions accommodate a smaller volume of people.

Not only would the range of occupants be dynamic and diverse, but the adaptive nature of the building would allow for a shift in sensory input allowing 
a widening in the breadth of individual experience.

Inspiration for such a dynamic design proposal comes from Terry Riley's musical composition "In C" composed in 1964. The piece is comprised of fiftythree separate numbered musical phrases ranging in duration from half a beat to thirty-two beats. The performance direction stipulates that "Patterns are to be played consecutively with each performer having the freedom to determine how many times he or she will repeat each pattern before moving on to the next. As an ensemble it is very desirable to play sottly as well as loudly, and to try a diminuendo and crescendo together. Each pattern can be played in unison or canonically in any alignment with itself or with its neighbouring patterns. One of the joys of "In (") is the interaction of the players in polyrhythmic combinations that spontaneously arise between patterns.." If the piece is properly played some quite fantastic and unicue musical shapes arise and disintegrate as the group moves through the piece.

It is important not to hurry from pattern to pattern, but to stay on a pattern long enough to interlock with other patterns being played. As the performance progresses performers should stay within two or three patterns of each other. It is important not to race too far ahead or to lag too far behind."

The piece speaks to the notion of improvisation while still staying within the boundaries of a fixed notation and compositional franework. The composer creates the boundaries and then stipulates the level of flexibility within them. In doing so each performance is unique from any other, and can be performed or manipulated to suit various renue s audiences, instrumentation, and time frames. The new Ogilyy Building reflects the concepts and logic established by "In (". Similar to how Riley has composed 53 patterns which in themselves are rigid, the architecture of the building mimics this with the movable wall partitions within the fixed space of the existing heritage structure. Their geometry, like the patterned

\footnotetext{
43 Wikinedia_In_. February $2012<\mathrm{http}: / /$ en.wikipedia.org/wiki/In_C $>$.
}

44 Wikinedia-InC. February $2019<$ http://en.wikipedia.org/wiki/In_C $>$. 
musical phrases, is fixed; however, the performer/user possess the flexibility to manipulate them in the required and desired way. In following this framework the element of subjectivity within architecture is highlighted: where spatial restrictions are not limited to one configuration. In contemporary mall atmospheres the visual, sonic, and tactile experiences are created through the intersection of elements, be it the low lighting or loud music, into a pre-existing and restricted space. Through this proposed configuration the possibility now exists to dynamically create a desired experience, with emphasis on the auditory, in a more integrated and effective way.
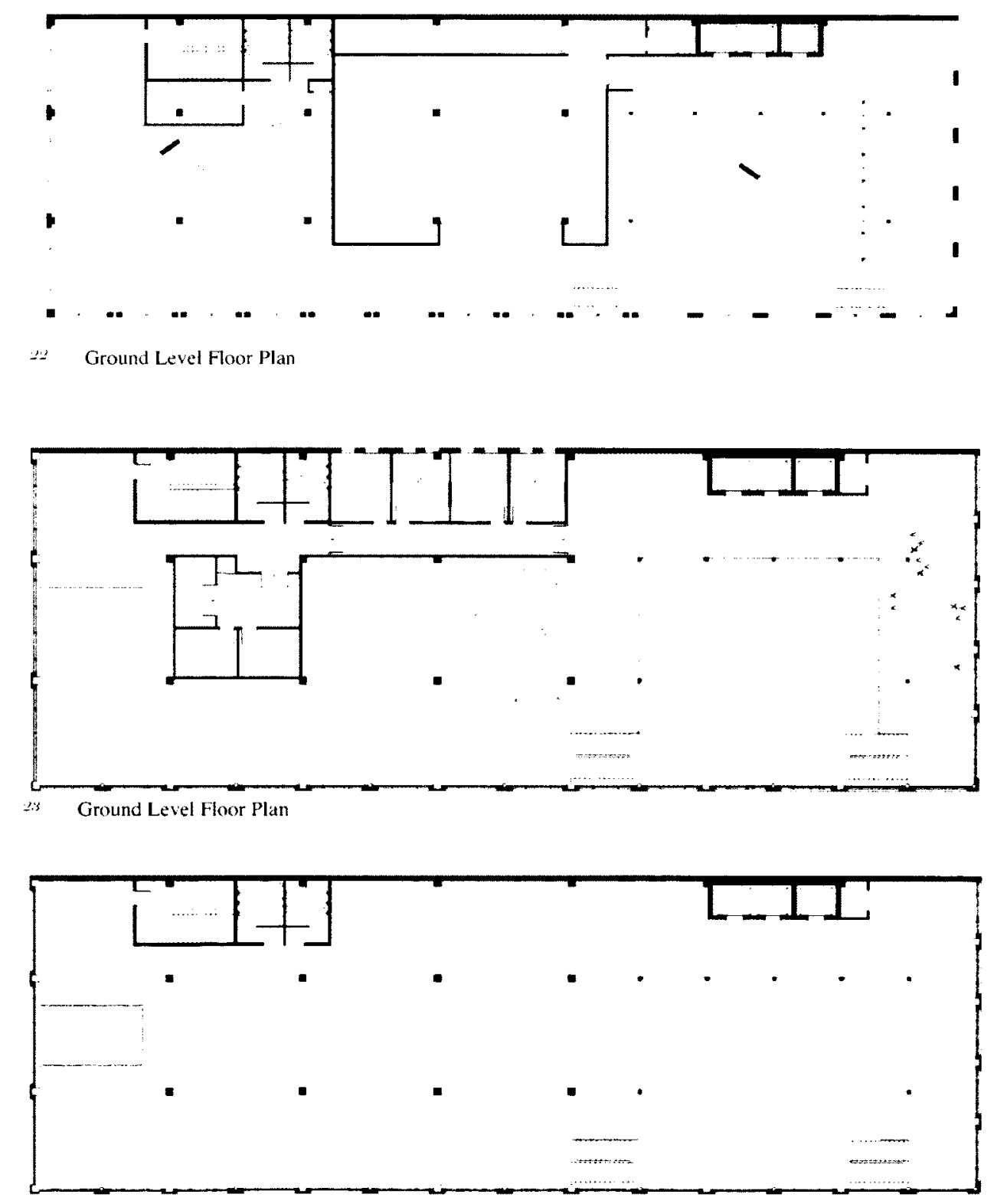

Third Level Floor Plan (Standard) 


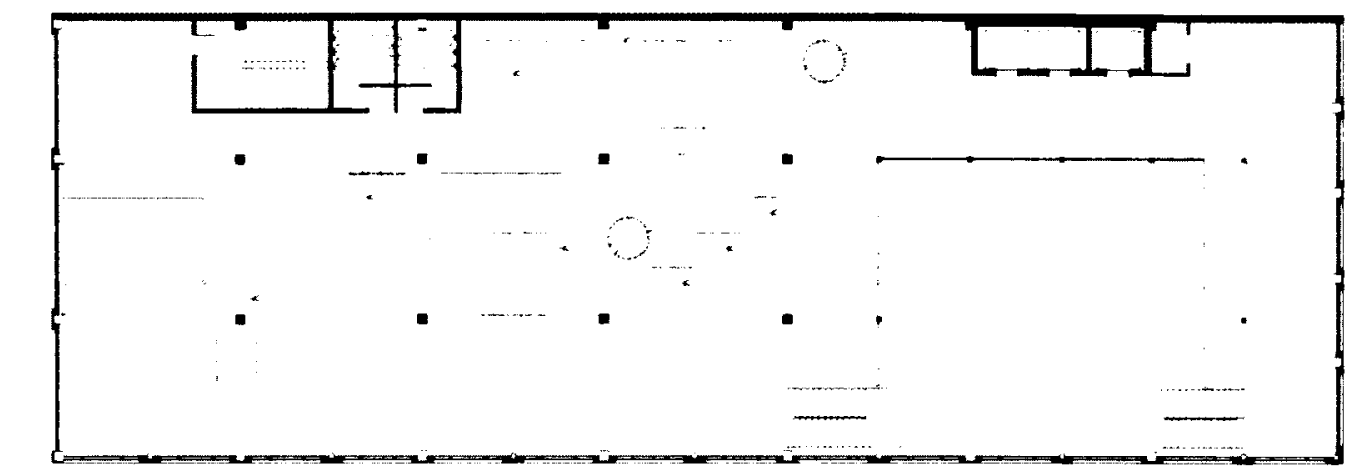

Fourth Level Floor Plan
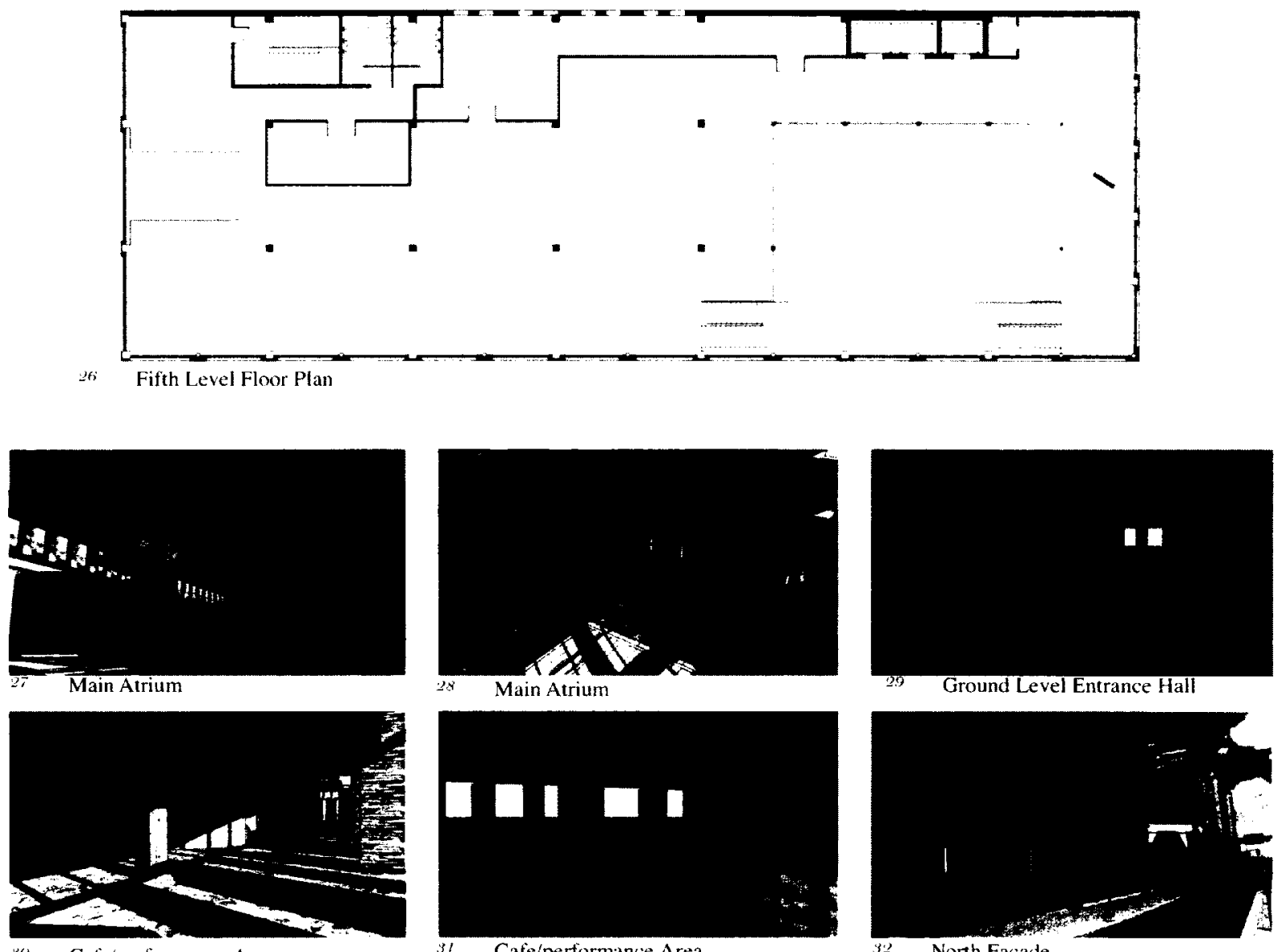

Cafe/performance Area

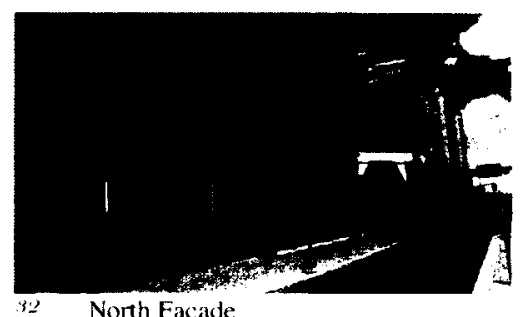




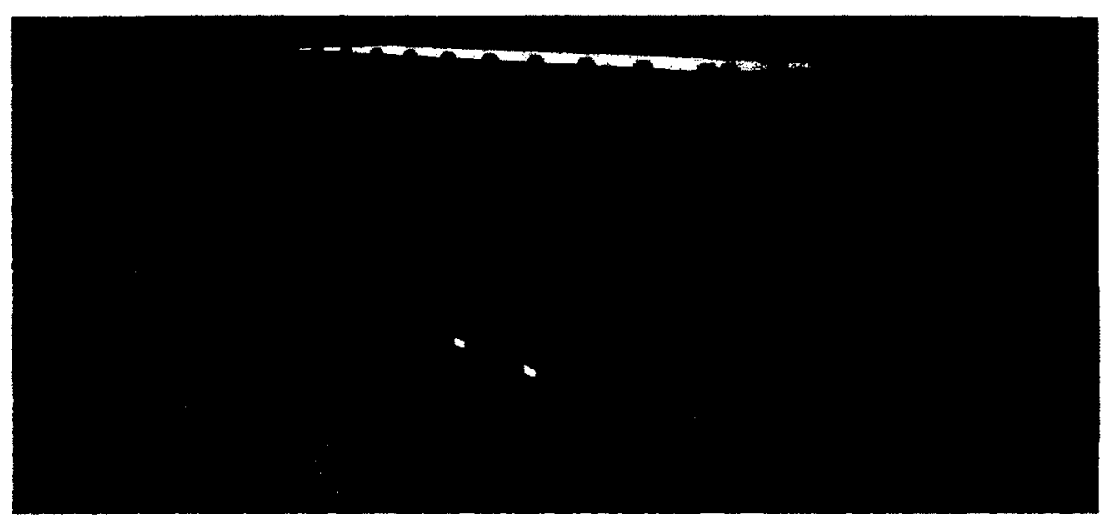

3.3 Building Persepctive

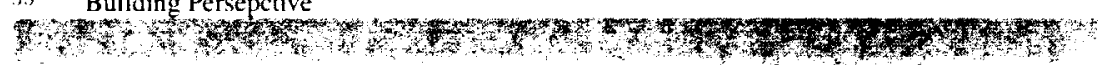
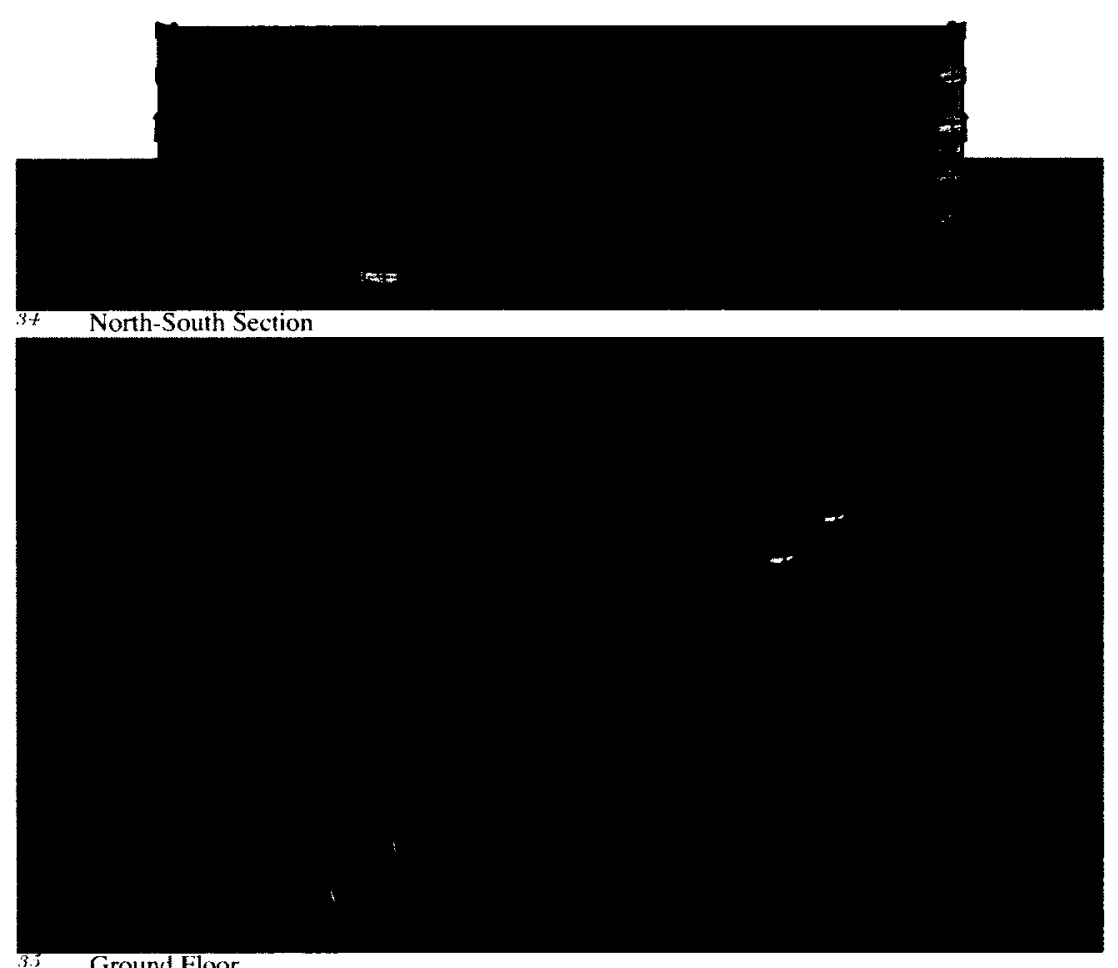

Ground Floor

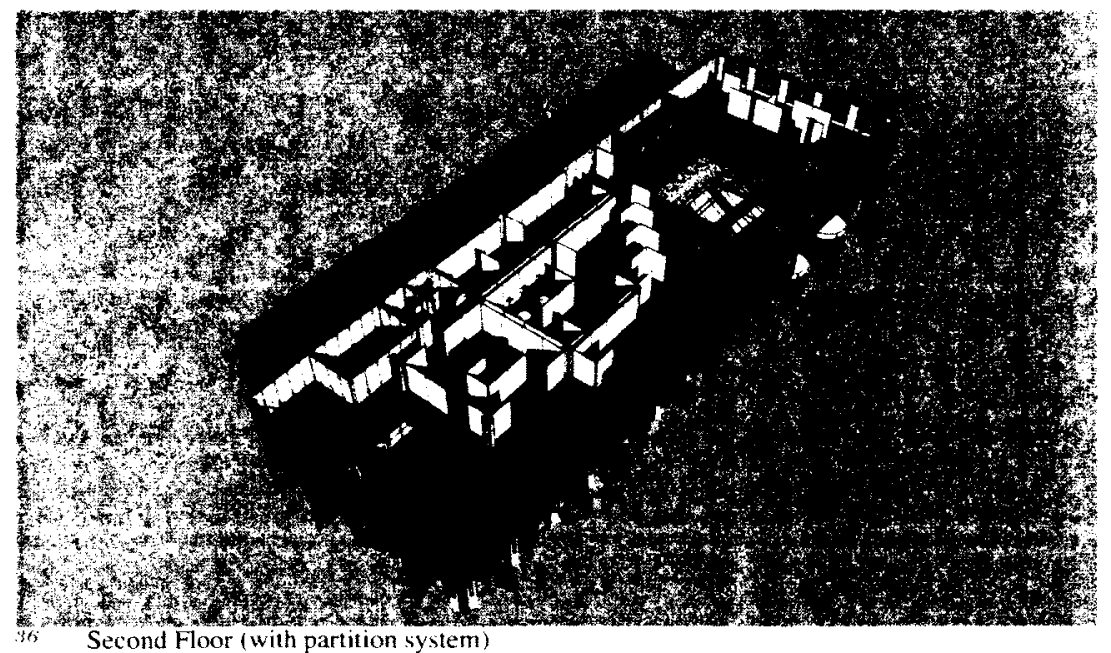

Second Floor (with partition system) 


\section{Sonic Design}

While the physical design parameters of the building play a crucial role in the user experience, such as location of walls, room proportion, window placement, and functional program, there is also the need for a sonic design. The proposed design for the Ogilvy building takes into account the varying sonic conditions and events of the space, and incorporates them with newly implemented sonic events within the built physical space of the building. In doing so the sonic properties of each space are at the forefront of shaping the experience of the space.

By taking into account the Acoustic Ecology (study of sounds and individual entities) of the building and isolating the different types of sounds, the opportunity exists for their interactions with each other to be manipulated.

There are a seemingly endless number of ways that sound can be produced. The way in which a sound is understood is a reflection of how and where it is being produced. For example, is the sound emanating from a static point, or a moving point - is it a projected sound, or naturally occuring sound? As referenced in the glossary on page 1 , several types of sound qualities have been defined as they will exist within the Ogilvy building.

The first is ambient sound, defind as the background sounds not necessarily in the forefront of the sonic experience such as mechanical sounds from the building. The second is point source sound which is sound emanating from one source - related to acoustical footprint. In this case an example is the individual within a space. Their acoustical footprint is comprised of their own speaking voice, footstep, whistle, and clothing noise The Third is acoustic projected source sound. These sounds emanate from a specific acoustical object with the intention of projecting its range. In the Ogilvy building the majority of these sounds are produced by musical instrument or musical event. The last is amplified projected source sound. It is similar to an acoustic projected source sound, 
however, regulated electronically through amplification. In doing so the volume of the projection can be controlled and the original source of the sound can vary from its projection point. In the Ogilvy Building these sounds are realized in the speaker door system (fig. 37).

The sonic drawings depict each different type of sound (fig 38-42).

The ambient sound is represented by the transparent green; its perceived intensity varies from space to space. The more intense the perceived ambient sound, the more opaque and visible is the green. For example, in the grocery store area on Level 1, the ambient sound would be high as a result of the fridges/freezers, pushing of grocery carts, and the sounds of cash registers. In contrast, around the piano, the perceived intensity of the ambient sound is far less owing to the fact that the acoustic projected sound of the piano would dominate the space.

Point Source Sounds are represented by a light blue glow. The primary point source sound comes from the individual people within the space. As they are constantly moving the origin point of the sound remains fixed in reference to the sound emitted (the click of a heel for example always comes from the individuals feet). However, their movement through the space creates dynamic sonic conditions (represented by the trailing blue haze behind each PSS).

Acoustic Projected Source Sounds are represented by the radiating circles of greyish pink. The further away one moves from the source, the less intense the sound becomes. The origin of the sound is fixed, and resonates through the space until stopped by the physical properties such as walls or ceilings.

Amplified Projected Source Sounds are represented by the small radiating circles of greyish pink. In this application, the APSS comes from the speaker system in the doors (see Speaker System Details section)

The door speaker projection system draws on the notion of Acousmatic sounds, where one cannot see the origin of the sound source. Strategically placed throughout the building's upper levels are microphones in varying sonic atmo- 
spheres (indicated by a small yellow circle). The recorded sounds are directly transmitted in real time to speakers located within the width of the door. As the doors themselves pivot along a central axis pole the directionality of the projected sound is not fixed and can easily be changed. This can have a variety of different effects. For an individual walking by on the street as they move along the sidewalk they hear the sounds from within the building, creating a sense of wonder and curiosity that draws them in. This mixing of the projected speaker sounds with the real world sounds around them creates an interesting dynamic. They also play on the notion of Acoustical Memory; someone leaving the building who had recently been shopping in a store where one of the microphones was located, whether aware of it or not, creates a memory link to the sonic environment in which they were just a part of.

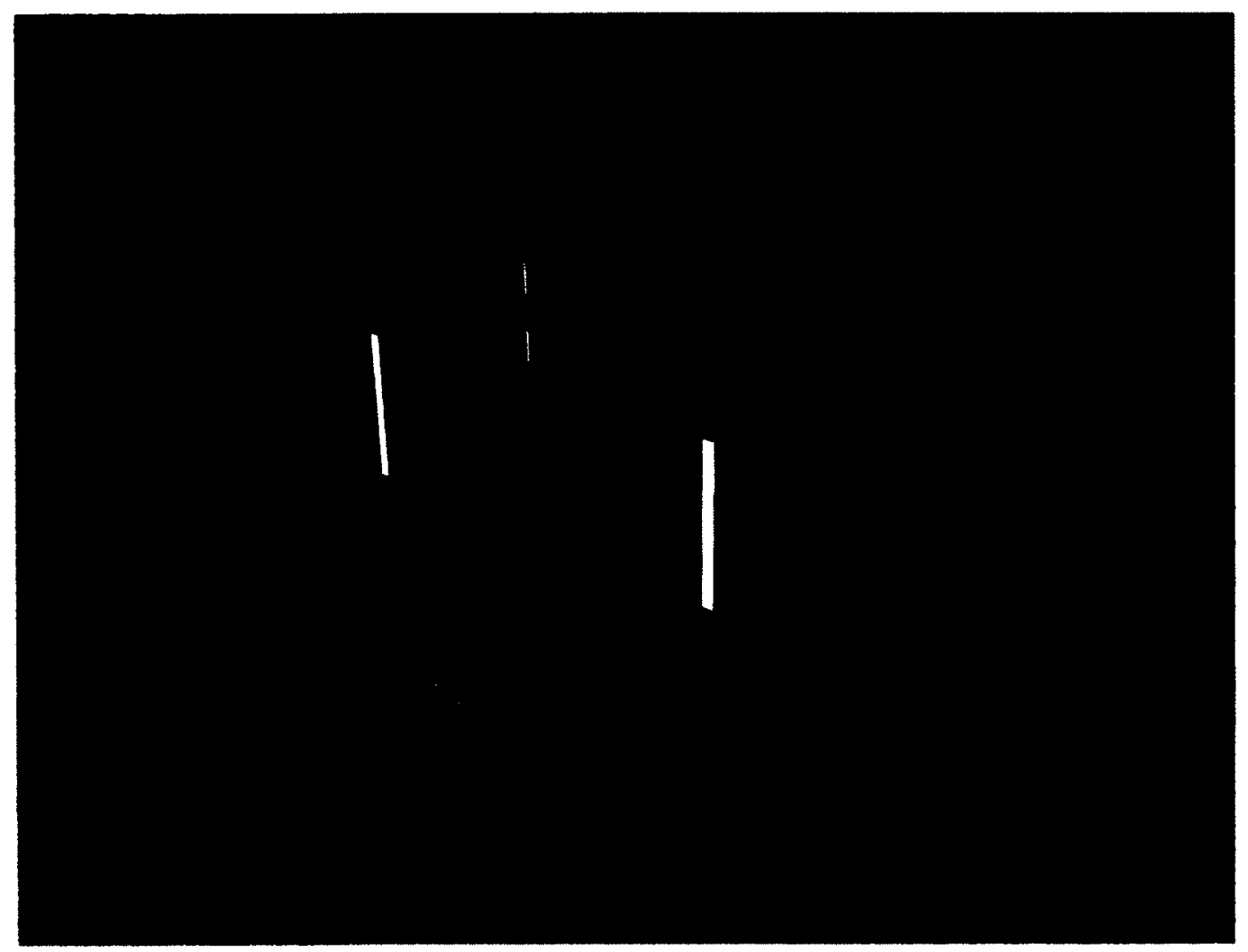

Speaker Door Detail 


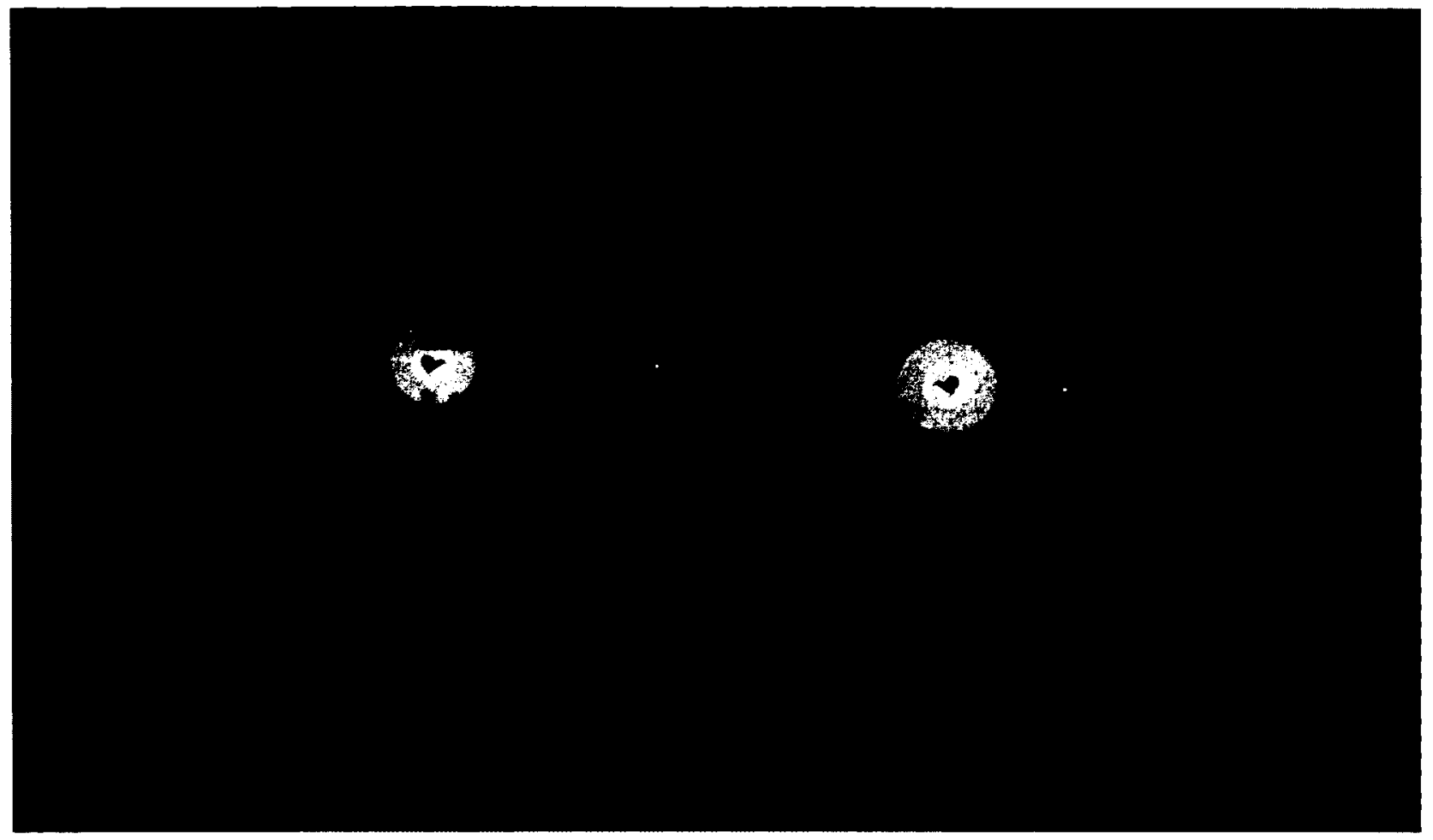

Ground Level Sound Plan (open)

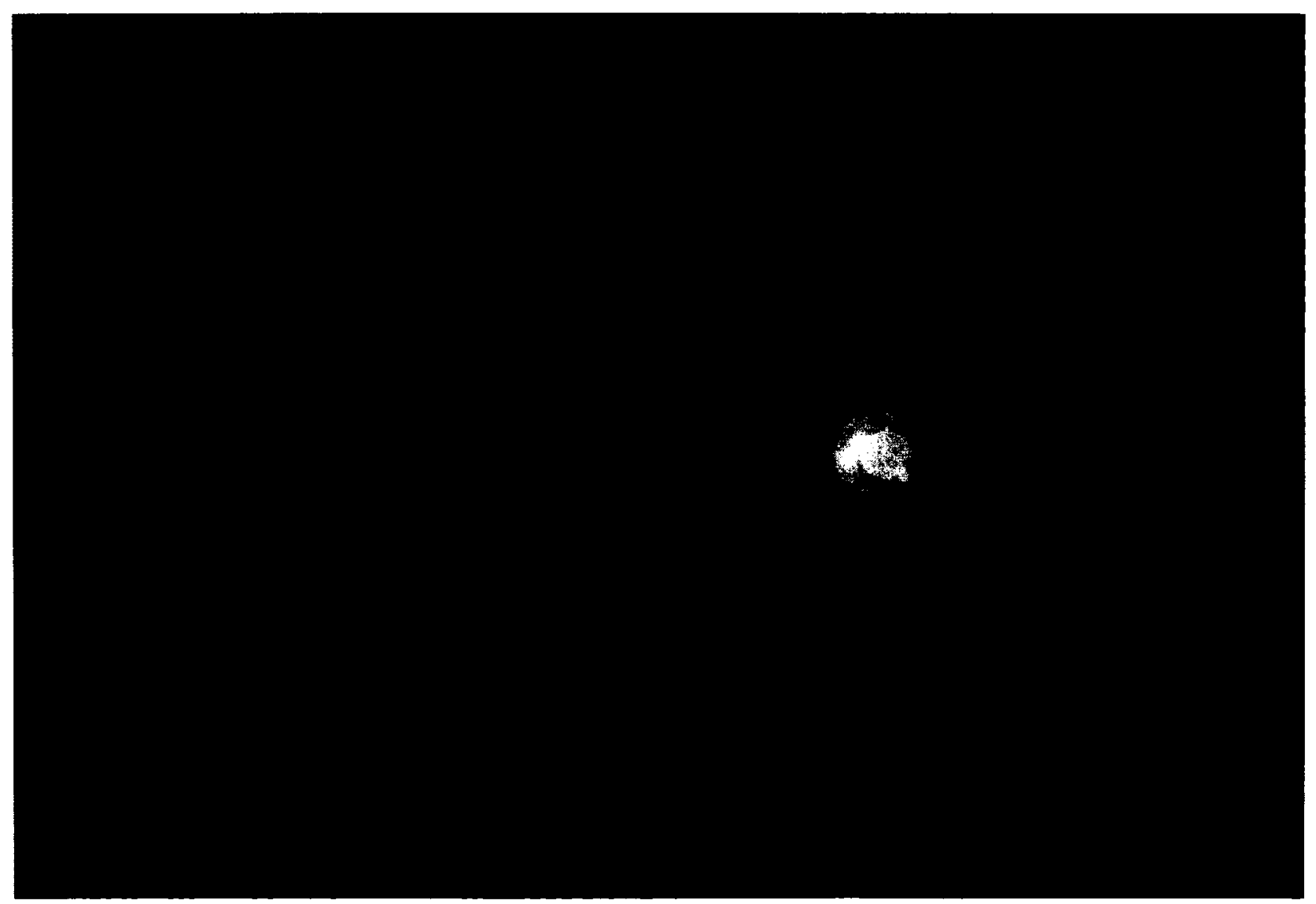

Ground Level Sound Plan (closed) 


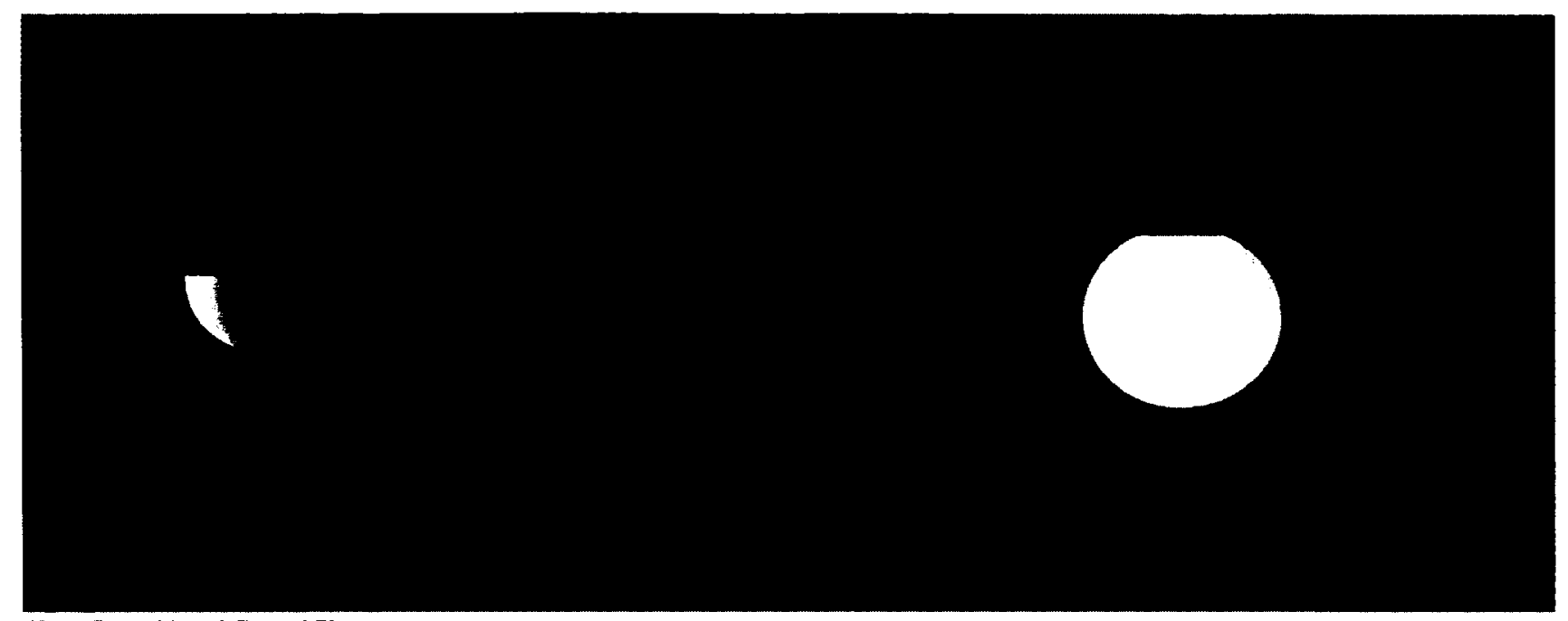

Second Level Ground Plan

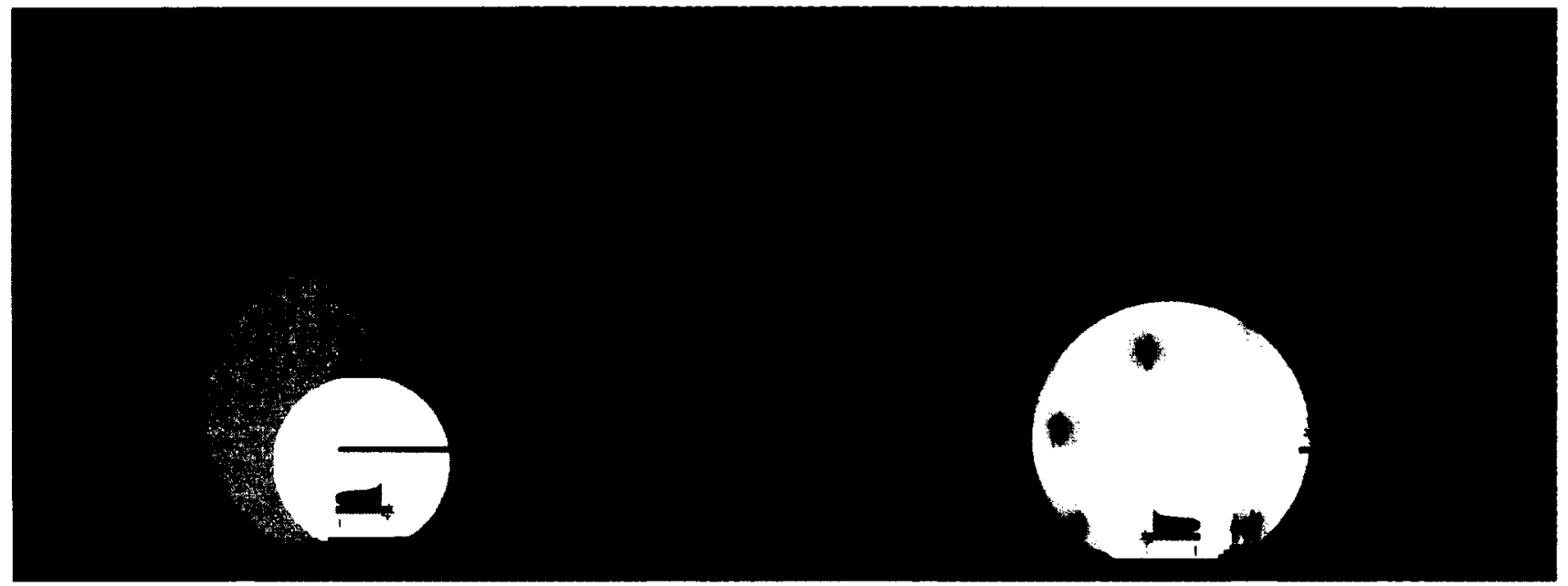

+1 North - South Sound Section

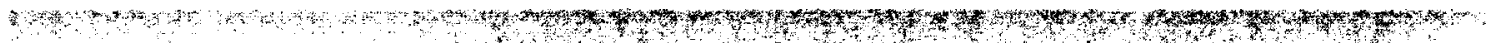

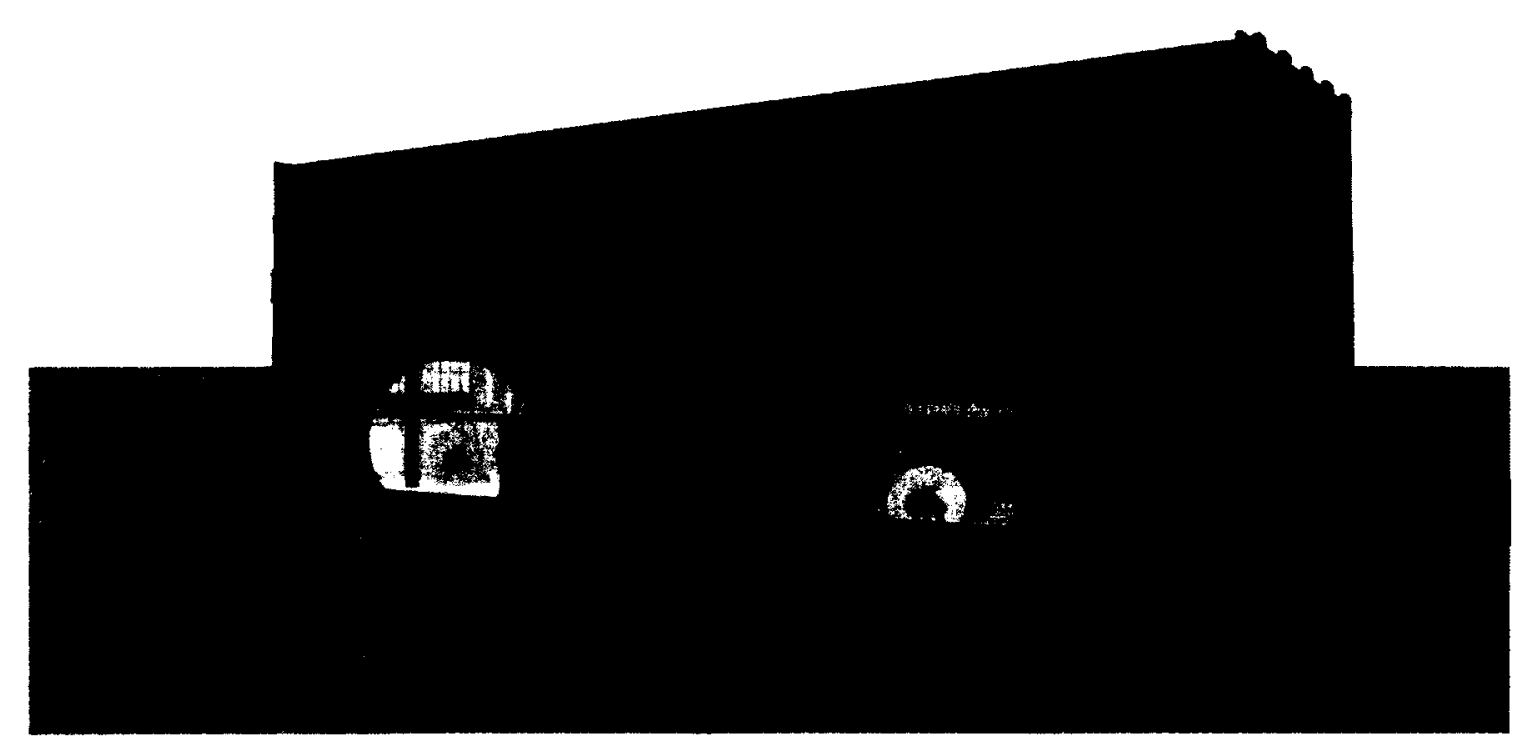

Sound Section 
As a result of such a design the corridor shifts from being a separate extermal element of the mall, becoming integrated within the various boutiques, and is imversely dictated by the flow of people within the space. This combines the different types of people (individual and masses) into a new dynamic and adaptable group. The space becomes adaptable depending on the level of activity and the conditions created by the store when manipulating their flexible perimeters in defining their sense of openness. Through altering the permeability of the space, as well the volumetrie proportions, the sonic atmosphere has the ability to drastically vary from one space to another. This is in direct contrast to the status quo, where the entirety of the mall sits within the same basic sonic intensity and properties. In addition to the adaptable partitions, the space will be programmed to include specific and unique sonic events by way of a performance space and cafe/gallery (fig. 27-31). As seen in fig. 22 and 38 the cate features a separate performance area and piano. The ambient noise of the patrons and the musical noise of the performance coupled with the mechanical noise of beverage production will create a dynamic sonic atmosphere. The cafe is located on the ground level and is incorporated with the pivot door system along the East and South sicies. Through the amalgamation of these various elements within the context of the Ogilyy building, the somic atmosphere of the space is no longer left up to chance, but rather becomes a specitically designed element. 


\section{Conclusion}

The redesign of the Ogilvy building and re-conceptualization of the shopping mall is influenced by a wide array of factors. In order to successfully design a truly beneficial sonorous space sonority in all facets must be understood. Architectural space and experience relies on intricate input from all the senses. Looking at the various ways in which sound is perceived and personified provides a thorough foundation in which architectural design can be based. In Part 1, this thesis established the profound effect that noise and sound have on ones quality of life, and the influence it has in establishing social, cultural, and socio-economical constructs. It has highlighted the psychological and physiological effects of sound on the human body, therefore strengthening the argument that the architectural spaces people inhabit need to take into account their sonority.

To successfully accomplish this, this thesis explored the representation, manipulation, and representation of sound in varying mediums. These findings then informed the way in which sound could be manipulated, personified, and represented within the architectural condition. The Futurists and Russolo's The Art of Noise strengthens the argument that sound has a profound impact on shaping experience, and sound as a form of expression. Russolo highlights the different types of sounds that can exist, and proposes their deconstruction and reassembly. This method parallels the design of the Oglivy building where individual and specific sounds and sound environments co-exist. Within the structure there are different types of sounds originating from various sources. For example, the sound of people talking in a café differs greatly in quality than the sounds of a small jazz band. As you move through the building you pass through different spatial volumes inhabited by these different sounds. Similar to the concepts of Russolo, the building itself becomes an orchestration of sounds. 
With this understanding further developed, the focus shifts to that of sound occupying space. The works of Luigi Nono, Xenakis, and David Byrne directly addressed the issue of using sound to manipulate space and vice versa. These works prove crucial in the design of the Ogilvy building as a musical composition shares many properties with architectural design. For example, Luigi Nono's work Prometeo shifted the typical arrangement of musicians within the orchestra. Opposed to sitting in a semi-circular arrangement opposite the audience, the musicians are situated above and around the audience in a specifically built ark. In doing so he places sound and projection in high regard which in turn changes the way in which the music and sound is experienced and becomes fundamental in how the musical work is perceived. In the design of the Ogilvy building similar importance is placed on the notion of sound production and projection. A new level of dynamic involvement is achieved through the creation of distinct sonic events. The door speaker system, the café, the performance space, the pianos and the interactions of all the individual events redefine the sonic condition of the space and its perception. Xenakis implemented a similar strategy in his various works; for instance, the circular arrangement of audience with the musicians inserted within. It is the Philips Pavilion however that the Ogilvy building draws the most parallels. The Philips Pavilion exists as a truly specifically designed space where it is the aural experience that is of utmost importance. From the time the individual enters the space the main focus is sensory experience and manipulation. The design of the Ogilvy building is in line with the goals of the pavilion in terms of creating a designed sonic space. Both are heavily influenced by societal and cultural elements, and place the individual experience at the forefront. Lastly, David Byrne and Playing the Building utilize architecture to physically create sound and place the discovery of these sounds with the individual user. The Ogilvy building employs a similar idea where the occupants through their movements in the space and interactions with the building create the sonic environment. The 
amount of sound within the building is a by-product of the volume of people within the space and how they decide to use it. The users can manipulate the partition system in such a way to either negate or project sound. The activity in the performance areas, bustle in the coffee shop, and use of the door speaker system all rely on user input, and user experience.

By studying the ways that musical sound is represented within a score and translated into a performance one can understand the Ogiliy design process. Where the musical score encapsulates sound, space, and time the architectural process does the same. The end result is the newly designed Ogilvy building that utilizes the architectural spatial conditions as ressels for sound.

As a result of these investigations the shopping mall redux is successfully achieved. A place that previously engaged very little concern for the sonorous is now one that is intrinsically connected with it. This design process further strengthens the social, cultural, and economic impact of the mall by creating a positive atmosphere through sonic design in which to shop, risit, be entertained and socialize. The architectural experience transcends the original and basic reliance on the sense of vision to create a harmonious sensory input that encapsulates all of the senses, with emphasis on audition. The soundscape of the mall is now an adaptive and dynamic center that responds directly to the user. Architecture can now be heard.

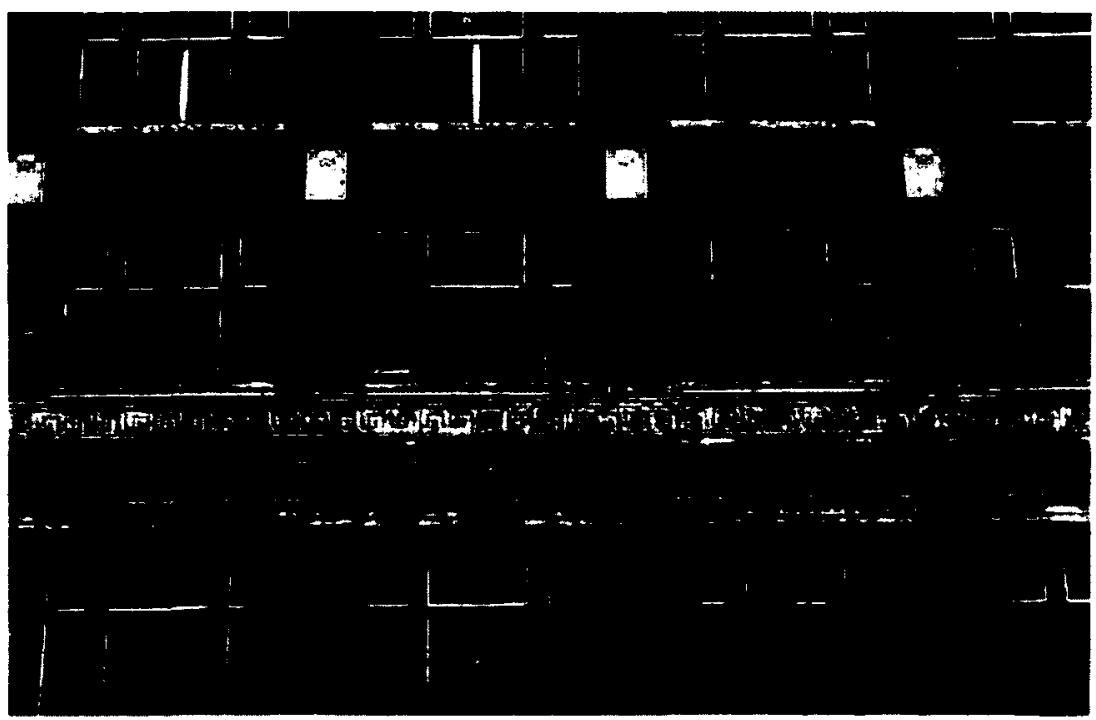

4.3 Ogilvy Building East Facade detail 


\section{List of Figures}

1. Nolan Cipriano. UNTITLE. (sketch).

2. Nolan Cipriano. BASICALLA SAN LUCA. (photograph) February 2011

3. Luigi Rusollo. UNTITLED. (Online Image) Available at: http://uwu.google.ca/ imgres?imgurl=http://w.w.unknown.nu/futurism/images/intonarumori.gif\&imgrefurl=http://www.unknown $\mathrm{nu} /$ futurism $/$ noises.html $\& \mathrm{~h}=2698 \mathrm{w}=408 \& \mathrm{~s} z=1.91 \& \mathrm{tbnid}=\mathrm{xp}-\mathrm{mHokbvaUUM}: \& \mathrm{tbnh}=82 \& \mathrm{tbnw}=125 \& \mathrm{kprev}=1$ search\%sFq\%sDLuigi\%2BRussolo\%26tbm\%3Disch\%26tbo\%sDu\&zom = 1 \&q=Luigi+Russolo\&usg=_cBVod96AhZwU:_Z8xsnBPF55tY=8sa=X\&ei=C-J8T5LIKYqy8QSA9pz8DA\&ved=0CCAQ9QEwAw

4. Renzo Piano. SKETCH (Online Imate) Available at: http://www.gongle.ca/ imgres?'imgurl=http://30.media.tumblr.com/tumblr_mod5j86F.5Y 1qlwu5wo1_500.jpg\&imgrefurl=http://conceptsketch.tumblr.com/page/2\&usg = _bx-MF86etK.2GDH2gQ-gZdbMilzs=8h=3.50\&w $=500 \& \mathrm{sz}=49 \& \mathrm{~h}]=\mathrm{en} \& \mathrm{st}$

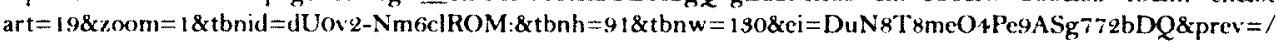
search\%sFq\%3Dprometeo\%2Brenzo\%2Bpiano\%26um\%3D1\%26hl\%3Den\%26safe\%3Doff\%26client\%3Dsafari\%26

sa\%3DN\%26rls\%3Den\%26tbm\%3Disch\&um $=1$ \&iths $=1$

5. Renzo Piano. THE ARK. (Online Image) Available at: http://www.google.ca/ imgres?imgurl=http://3.bp.blogspot.com/_ipoW 8antlyM/TQeclizsSI/AAAAAAAAAZM/ZGQJBOsXF.gM/ s I $600 /$ Piano_Prometeo_4.jpg\&imgrefurl=http://akortakap.blogspot.com $/ 2010 / 12 /$ musikaren-espazioa-histori-

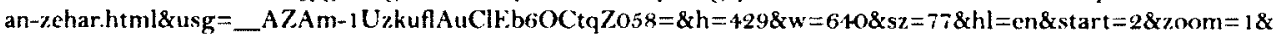
tbnid=z9se2ixSkhFuQM:\&tbnh=928tbnw =1978kei=ZOJ8T8rZIom9AT33NSTDQ\&prev $=/$ search\%3Fq\%3Dpro meteo\%2Bnono\%26um\%3 1\%26hl\%s Den\%26safe\%3Doft\%26client\%3Dsafari\%26sa\%3DN\%26rls\%3Den\%26tbn $\%$ sDisch\&um $=1$ \&itbs $=1$

6. Xenakis: METASTASIS SCORE. (Online Image) Available at: htp://www. gongle.ca $/$ imgres? $q=$ metastasis + xenakis\&num $=10 \& u m=1 \&$ hl $=\mathrm{en} \& s a f e=o f f \& c l i e n t=$ safari\&rls $=$ en\&biw $=118+\& b i$ $\mathrm{h}=603 \& \mathrm{tbm}=$ isch\&tbnid=KLYwXR_oCgoMCM:\&img refurl $=\mathrm{http}: / \mathrm{ww}$ wauto-assembly.com $/ \mathrm{blog} / \% 3 \mathrm{Fp} \% 3 \mathrm{D} 12$ o\&docid=tqh2XUtgvgoOnM\&imgurl=http: $/ / \mathrm{www}$.auto-assembly.com $/ \mathrm{blog} / \mathrm{wp}$-content $/$ uploads $/ 2006 / 12 / \mathrm{meta}$.

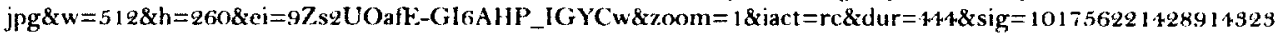
$221 \&$ sqi $=2 \&$ page $=1 \&$ tbnh $=81 \&$ tbnw $=159 \&$ start $=0 \& n d s p=20 \& v e d=1 \mathrm{t}: 429, r: 1, \mathrm{~s}: 0,1: 72 \& \mathrm{tx}=23 \& \mathrm{t} y=15$

7. Xenakis: MUSICAL SCORE. (Online Image) Available at: htp://www google.ca/imgres? $\mathrm{q}=$ metastasis + xenakis\&num $=10 \& u m=1 \& \mathrm{hl}=\mathrm{en} \& \mathrm{safe}=$ off\&client $=$ safari\&rls $=\mathrm{en} \& \mathrm{biw}=$

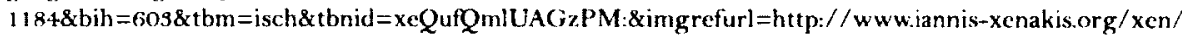
works/works 1 .html\&docid=n504NV-CrOgVxM\&imgurl=http://www.iannis-xenakis.org/partitions/ais.

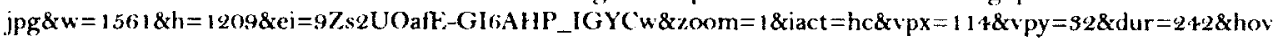
$h=1+1 \&$ hov $\mathrm{w}=164 \& \mathrm{tx}=153 \& \mathrm{ty}=121 \& \mathrm{sig}=10175622142891+3232218 \mathrm{sqi}=2 \&$ page $=1 \& \mathrm{tbnh}=130 \& \mathrm{tbnw}=1 .+6 \& \mathrm{sta}$ $r t=0 \& n d s p=20 \& v e d=1 t: 429, r: 7, s: 0, i: 91$

8. Xenakis: TERRETEKTORH. (Online Image) Available at: http://www.gorgle.

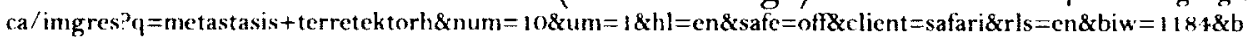

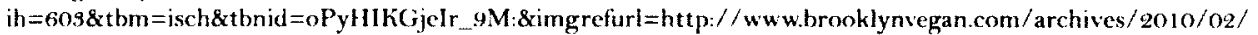
avant-garde_com.html\&docid =z.bWSfmLLluuq8M\&imgurl=http://www.brooklynvegan.com/img/musice/IX 17 .

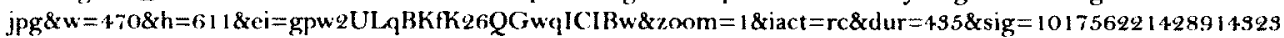
$221 \&$ sqi $i=2 \&$ page $=1 \&$ tbnh $=124 \&$ tbnw $=95 \&$ start $=0 \& n d s p=21 \& v e d=1$ t: $: 429, r: 1, s: 0, i: 72 \& t x=5 ; \& t y=53$

9. Xenakis: METASTASIS GLISSANDO. (Online Image) Available at: http:// www.gongle.ca/imgres? $q=$ metastasis + xenakis\&num $=10 \& u m=1 \& h l=c n \& s a f e=$ of $\&$ client $=$ safari\&rls $=$ en $\& b i w=11$

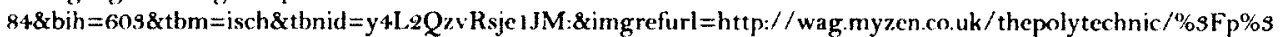
D2s9\&docid=GEBAz75XzzAo6M\&imgurl=http://wag.myzen.co.uk/thepolytechnic/wp-content $/$ files $/ 2009 / 03 /$

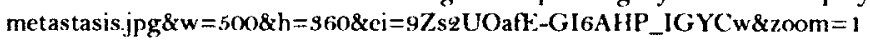

10. Xenakis: PHILIPS PAVILION. (Online Image) Available at: http://www. google.ca/imgres?q=philips + pavilion\&um $=1 \& \mathrm{hl}=\mathrm{en} \&$ safe $=$ off\&client $=$ safari\&rls $=\mathrm{en} \& \mathrm{biw}=11 \mathrm{R}+\& \mathrm{bih}=603 \& \mathrm{tb}$

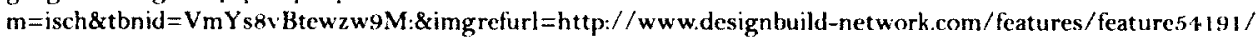
feature 5+191-6.html\&docid=6DlodLSYdsperM\&imgurl=http $/ /$ www.designbuild-network.com/uploads/fea-

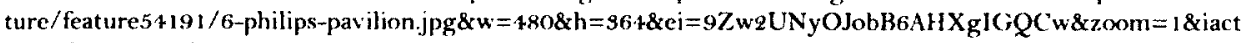

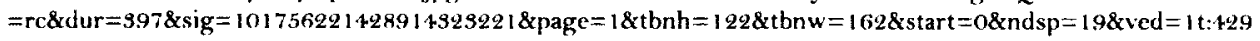
r: $\$, s: 0, i: 78 \& \mathrm{tx}=1+2 \& \mathrm{ty}=85$

11. Xenakis: PHILIPS PAVILION IMAGE. (Online Image) Available at: http: / wwwgoogle.ca/imgres? $q=$ poeme +electronique\&um $=1$ \&hl=en\&safe $=$ officlient $=$ safari\&sa $=X \& \mathrm{rls}=\mathrm{cn}$

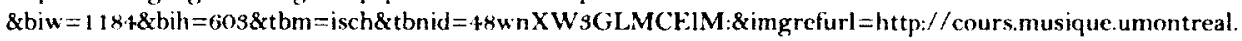
ca/MUS 1217/Partitions/Varese_Poeme/presentation.html\&docid=dOGJFcERfZhAfM\&imgurl $=$ http://cours. musique.umontreal.ca/MUS1217/Partitions/Varese_Poeme/images/varese $1 . J P G \& w=409 \& \mathrm{~h}=403 \&$ ei $=\mathrm{J} 502 \mathrm{UNm}$

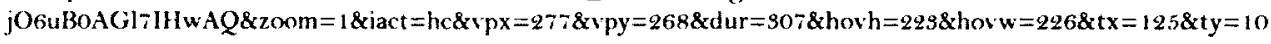

$6 \&$ sig $=101756221+2891+323221 \&$ page $=18$ thnh $=126 \&$ tbnw $=1128$ start $=0 \&$ ndsp=20\&ved $=1 \mathrm{t}: \mathrm{k} 29, \mathrm{r}: 7, \mathrm{~s}: 0, \mathrm{i}: 91$ 
12.David Bynre. PLAYING THE BUILDING (Online Image) Available at: htp:// www blueprintmagazine.co.uk/wp-content/uploads/2009/os/david-byrne-playing-the-building1.jpg

13. Unknown. RIDEAU CENTRE PLAN (Online Image) Available at: http://www. rideaucentre.com/en/Pages/defaultaspx

14. Unknown. RIDEAU CENTRE (Online Image) Available at: http://upload.wikimedia org/wikipedia/commons/d/dc/Rideau_CentreXmas.JPG

15. Nolan Cipriano. SITE PLAN (Photoshop Drawing)

16. Nolan Cipriano. OGLIVY BUILDING NORTH FACADE (Photograph)

17. Nolan Cipriano. OGILVY BUILDING NORTH-EAST (Photograph)

18. Nolan Cipriano. OGILVY BUILDING EAST FACADE (Photograph)

19. Nolan Cipriano. OGILVY BUILDING SOUTH FACADE (photograph)

20. Unknown. WEST EDMONTON MALL (Online Image) Available at: http://2. bp.hlogspot.com/_iwerzWvxxtQ/TKprM_U-Dul/AAAAAAAAA5s/YC-jmdW_OvQ/sicm/mall7.jpg

21. Unknown. CLEVELAND ARCADE (Online Image) Available at: htop//o.tqn. com $/$ d/cleveland $/ 1 / 0 / n /$ L $/-/$ / 09. .jpg

22. Nolan Cipriano. GROUND LEVEL PLAN (AutoCAD Drawing)

23. Nolan Cipriano. SECOND LEVEL PLAN (AutoCAD Drawing)

24. Nolan Cipriano. THIRD LEVEL PLAN (AutoCAD Drawing)

25. Nolan Cipriano. FOURTH LEVEL PLAN (AutoCAD Drawing)

26. Nolan Cipriano. FIFTH LEVEL PLAN (AutoCAD Drawing)

27. Nolan Cipriano. MAIN ATRIUM PERSPECTIVE (Sketch-up Drawing)

28. Nolan Cipriano. MAIN ATRIUM PERSPECTIVE II (Sketch-up Drawing)

29. Nolan Cipriano. GROUND LEVEL ENTRANCE PERSPECTIVE (Sketchup Drawing)

30. Nolan Cipriano. CAFE/PERFORMANCE SPACE PERSPECTIVE (Sketchup Drawing)

31. Nolan Cipriano. CAFE/PERFORMANCE SPACE PERSPECTIVE II

(Sketch-up Drawing)

32. Nolan Cipriano. NORTH FACADE PERSPECTIVE (Sketch-up Drawing)

33. Nolan Cipriano. BUILDING PERSPECTIVE (Sketch-up Drawing)

34. Nolan Cipriano. NORTH-SOUTH SECTION (Sketch-up Drawing)

35. Nolan Cipriano. GROUND FLOOR PERSPECTIVE (Sketch-up Drawing)

36. Nolan Cipriano. SECOND FLOOR PERSPECTIVE (Sketch-up Drawing)

37. Nolan Cipriano. SPEAKER DOOR DETAIL (Sketch-up Drawing)

38. Nolan Cipriano. GROUND FLOOR SOUND PLAN - OPEN (AutoCAD/

Photoshop Drawing)

39. Nolan Cipriano. GROUND FLOOR SOUND PLAN - CLOSED (AutoCAD/

Photoshop Drawing)

40. Nolan Cipriano. SECOND FLOOR SOUND PLAN (AutoCAD/Photoshop

Drawing)

41. Nolan Cipriano. SOUND SECTION (AutoCAD/Photoshop Drawing)

42. Nolan Cipriano. SOUND SECTION PERSPECTIVE (AutoCAD/Photoshop

Drawing)

43. Nolan Cipriano. OGILVY BUILDING EAST FACADE DETAIL (Photo-

graph) 


\section{Bibliography:}

Blesser, Barry. Spaces Speak. Are you Listening?. Cambridge: MIT Press, 2007

Brooks, Christopher N. Architectural Acoustics. Jefferson, 2003.-

Federica Goffi-Hamilton. "Carlo Scarpa and the eternal canvas of silence." Architecture Research Quarterly 10.3-4. 2006.

Kahn, Douglas. Noise Water Meat: A History of Sound in the Arts. Cambridge, London: MIT Press, 2001.

Keizer, Garret. The Unwanted Sound of Everything We Want. New York: Public Affairs Perseus Press, 2010

Klodawsky, Helene. Malls R Us. Icarus Films, 2009. Film.

Labelle, Brandon. Acoustic Territories/ Sound Culture and Everyday Life. New York: Continuum International Publishing Group, 2010.

Lepper, Richard. The Sight of Sound: Music, Representation, and the History of the Body. London: University of California Press, 1995.

Levin, J Daivid. "Staging a Reading/Reading a Staging" Cambridge Opera Journal. 1997, Cambridge University Press: 47-71.

Martin, Elizabeth. Architecture as a Translation of Music. New York : Princeton Architectural Press, 1994.

McLuhan, Marshall. The Gutenberg Galaxy. Toronto: University of Toronto Press, 1962.

Page, Tim. The Glenn Gould Reader. New York: Knopf, 1984.

Schafer R. Murray. The Soundscape: The Tuning of the World. Rochester, $1977,1994$.

Shaw-Miller, Simon. "Thinking Through Construction: Notation-Composition- 
Event, The Architecture of Music" AA files. The Architectural Association: 38-88. Spring 2006.

Russolo, Luigi. The Art of Noises. Something else press, 1967.

Shaw-Milling, Simon. Visible Deeds of Music: art and music from Wagner to Cage. New Haven: Yale University Press, 1959.

Steiner George. In Bluebeards Castle. New Haven: Yale University Press, 1971.

Sterne Jonathan. The Audible Past. Durham \& London: Duke University Press, 2003

Sterne, Jonathan. Ethnomusicology, Vol. 41, No.1. (Winter, 1997), p22-50

Tenny, James. Meta + Hodos and META meta +Hodos. Hanover: Frog Peak Music, 1992.

Thomspon, Emily. The Soundscape of Modernity. Cambridge: MIT press.

Valery, Paul -translated by William McCausland Stewart. Dialogues: Eupalinos or the Architect. Princeton University Press, 1989 